\title{
System Characteristics Analysis for Energy Management of Power-Split Hydraulic Hybrids
}

\author{
Hyukjoon Kwon $1,2, *(1)$ and Monika Ivantysynova ${ }^{1,3}$ \\ 1 School of Mechanical Engineering, Purdue University, West Lafayette, IN 47907, USA \\ 2 R\&D Division, Hyundai Motor Company, Hwaseong 18278, Korea \\ 3 Maha Fluid Power Research Center, Lafayette, IN 47905, USA \\ * Correspondence: hkwon@live.com or kwon68@purdue.edu
}

Received: 8 March 2020; Accepted: 2 April 2020; Published: 10 April 2020

\begin{abstract}
Hydraulic hybrid powertrains provide an opportunity for specific applications, such as heavy-duty vehicles based on high-power density, which has not been included in other types of hybrid powertrains. Among the various architectures of hybrid vehicles, power-split hybrids have a greater possibility of producing better fuel efficiency than other hybrid architectures. This study analyzed the possible energy-saving characteristics of power-split hydraulic hybrid vehicles (HHVs); this has not been comprehensively described in previous studies. A typical configuration of power-split HHVs was modeled with the FTP-72 driving cycle using a novel simulation method that considered the dynamic and thermal behaviors together. The characteristics were analyzed in comparison to a power-split hydrostatic transmission (HST), which is designed with the same conditions except for hydraulic energy storage. The power-split HHV not only has a better fuel efficiency, but it also shows system energy-saving characteristics. The power-split HHV has more chances for engine idling, which is directly related to fuel consumption savings due to engine stop. Additionally, more engine idling time enables the system to operate in a more efficient area on the engine map by load leveling. The results for the system temperature show that the power-split HHV offers the possibility to deliver better thermal management because it prevents the waste of braking power, which is especially crucial for hydraulic systems in comparison to other power systems such as electric or mechanical power systems. The ease of thermal management results in less energy consumption for cooling down the system temperature by minimizing the cooling system, as well as in a better thermal stability for the hydraulic system. The power-split HHV characteristics analyzed in this study can be used to design and organize the system control logic while developing power-split HHVs.
\end{abstract}

Keywords: hydraulic hybrid vehicle; power-split hybrid; energy system modeling; energy management

\section{Introduction}

In recent decades, unstable petroleum oil prices, together with governmental environmental regulations, have been driving the automotive industry to develop new vehicle architectures with high fuel efficiency. Hybrid vehicles are one of the most popular alternatives to conventional vehicles. Even though hydraulic hybrid vehicles (HHVs) are less known and commercialized in comparison to hybrid electric vehicles, they have clear advantages, such as high-power capacitance and low-cost materials based on hydraulic systems [1,2]. Hydraulic systems have been widely utilized in construction and agricultural vehicles due to the high-power demand and the relatively low cost of materials [3-7]. Hybrid electric vehicles have higher energy density than HHVs, which makes them applicable for specific system architectures. In contrast, the great power density of HHVs offers superior technology in urban environments that require frequent stops and starts, which is suitable for applications, such 
as refuge trucks and buses [8-13]. Due to the characteristics of both systems, their advantages have been considered together for studies investigating hydraulic-electric synergy systems [14-17].

Hybrid vehicle architectures can mainly be divided into series, parallel, and power-split hybrids based on the way power flows through the systems. Among them, power-split hybrids have the advantages of series and parallel hybrids and the potential for better fuel economy if the system is designed properly [18]. Power-split hybrids utilize a planetary gear that divides the engine power into a mechanical path and a secondary power path. There are more than 1000 possible power-split configurations based on the combinations of planetary gear trains and power sources [10]. Recent studies for power-split hybrid electric vehicles have been published for different topics $[19,20]$, and also, for power-split HHVs, it has been steadily studied by a variety of researchers and institutions since the 1980s.

Recent research topics for power-split HHVs include different areas, such as dynamic analysis and controllers for passenger vehicles [21-25], experimental studies on hardware in the loop tests [26-28], concept car demonstrations, such as Hybrid Air by Peugeot [29], and system optimizations and optimal architecture studies for specific applications [10]. A recent study investigated the optimization system of a power-split HHV and reported energy savings up to $35 \%$ in comparison to a power-split hydrostatic transmission (HST) without considering engine management [30]. Although some studies have investigated the energy consumption characteristics of power-split hybrid architectures, they have primarily focused on the energy management of hybrid transmissions without considering other aspects, such as the energy-saving possibilities associated with the engine management and thermal management of hydraulic systems.

As hybrid electric vehicles, HHVs have possibility of saving energy in terms of regenerative energy, engine power load leveling and engine on-off control. In addition to those energy saving characteristics, HHVs have another advantage for thermal management since the fluid power system itself manages system temperature. For hydraulic systems, thermal management is crucial for energy management in terms of preventing the waste of loss energy and energy consumption for the cooling system. While there have been recent studies on thermal management for HHVs [31-34], no study has yet investigated details of energy management strategy for power-split HHVs together with the thermal characteristics. In this study, the details of the power management characteristics of power-split hydraulic hybrid architectures were studied using a system-level simulation. Firstly, a novel modeling method that considered the dynamical and thermal behaviors together was introduced and applied to analyze the details of the characteristics of the powertrain system. A power-split hydraulic hybrid was simulated and compared with a power-split HST as a typical non-hybrid hydraulic architecture. The simulation model for both systems was controlled to track the FTP-72 driving cycle, also known as the Urban Dynamometer Driving Schedule (UDDS) cycle, which is a typical city driving test cycle. In the comparison, the advantages of power-split HHVs over power-split HSTs were analyzed for power management including not only energy recovery during braking but also energy-saving possibility resulting from the engine operating conditions and thermal management.

\section{System Analysis}

Power-split hybrids include mainly three driving modes: power additive, full mechanical, and power recirculation modes. During the power additive mode (power-split mode), power flow from the engine splits into the mechanical path and secondary power path and they merge again before the final drive to drive the vehicle. For the full mechanical mode, all of the power is transferred through the mechanical path and it shows the highest efficiency among three driving modes. In the power recirculation mode, some of the power delivered through the mechanical path is recirculated through the secondary power path. The recirculated power merges with the power from the engine and transferred through the mechanical path again. Since system efficiency decreases when the recirculation amount increases, the power recirculation mode is undesirable for power-split hybrids. Figure 1 shows the schematics of the main driving modes for power-split hybrids. 


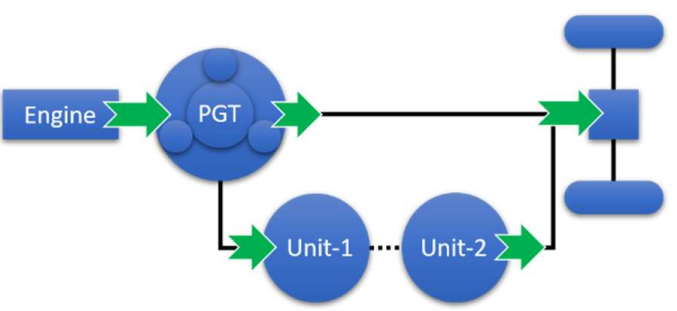

(a) Power Additive Mode

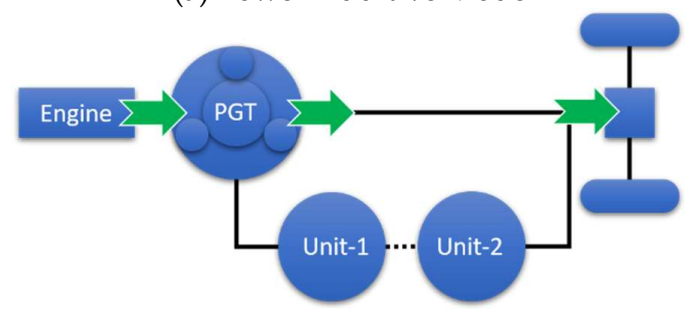

(b) Full Mechanical Mode

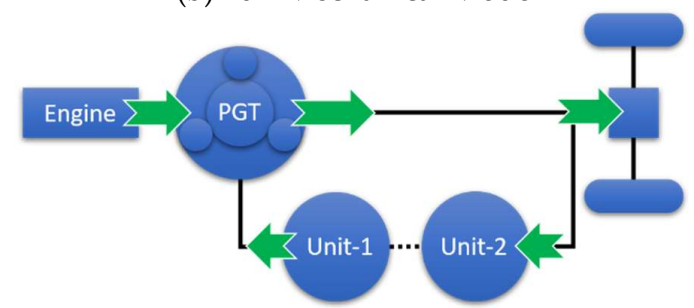

(c) Power Recirculation Mode

Figure 1. Schematics of the main driving modes for power-split hybrids.

The two main configurations of power-split hybrids are output coupled (or input split) and input coupled (or output split) configurations. Figure 2 shows the schematics of two main configurations of power-split hybrids. The difference between output coupled and input coupled configurations is the layout of the planetary gear train. The final drive is coupled with the secondary power path without a planetary gear train for the output coupled configuration, while the engine is coupled to the power source of the secondary path without a planetary gear train for the input coupled configuration.

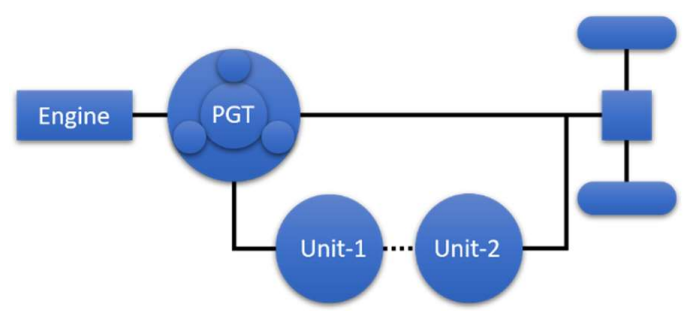

(a) Output-coupled Configuration

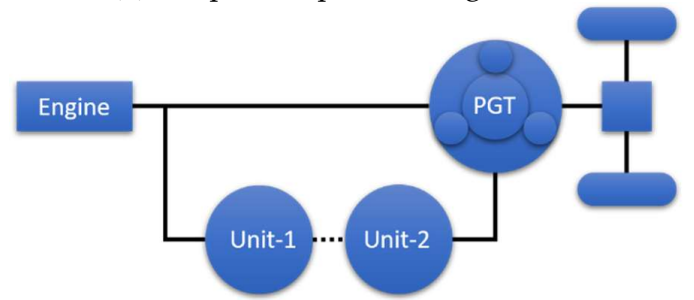

(b) Input-coupled Configuration

Figure 2. Schematics of two main configurations of power-split hybrids.

Figure 3 shows the efficiency of output-coupled and input-coupled power-split transmissions when the critical ratio $\gamma_{c r}$ is 2.8. The efficiency of output coupled and input coupled configurations 
shows different trends according to the speed ratio of the wheel and engine speeds. The efficiency of both configurations increases according to the speed ratio and decreases after the full mechanical point. The difference is that the output coupled configuration has a higher efficiency for a lower speed ratio and the input coupled configuration has a higher efficiency for a higher speed ratio. Output-coupled power-split architectures are more popular compared to input-coupled power-split one due to the possibility of the full-range single mode driving [35,36]. Among those configurations, an output-coupled power-split configuration was studied in this paper for analyzing characteristics of power-split hydraulic hybrids.

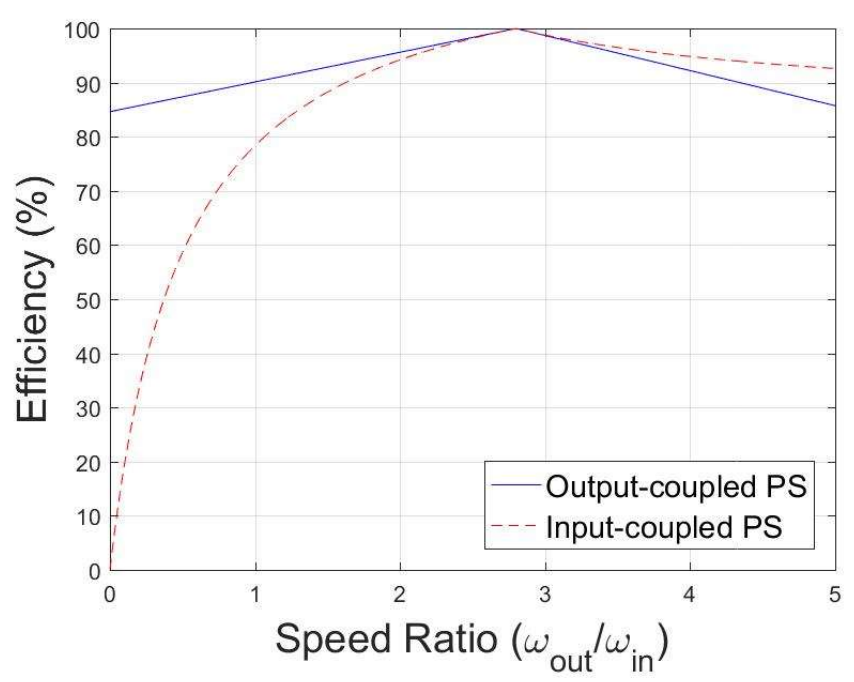

Figure 3. Efficiency of output-coupled and input-coupled power-split transmissions.

Figures 4 and 5 show the hydraulic circuits of a power-split HHV and a power-split HST based on output-coupled configurations, which were used for a system analysis in this study. For both systems, Unit-1 was connected to the ring gear of the planetary gear train and Unit-2 was connected with the final drive. In the hydraulic circuit, a charge pump supplied flow into the low-pressure system. In the power-split HHV, two accumulators were assembled with high- and low-pressure lines. While the Line-A keeps a high pressure in the power-split HHV, the high-pressure line between Line-A and Line-B switches according to operating modes. For system thermal management, the hydraulic system in the power-split HHV was cooled down by the flow from Line-B, which was maintained as the low-pressure line. There is a shuttle valve in the power-split HST due to the switching of the low-pressure line and flow through the cooler is selected based on the shuttle valve. Table 1 shows the component sizes for the power-split HHV and the power-split HST used in Figures 4 and 5.

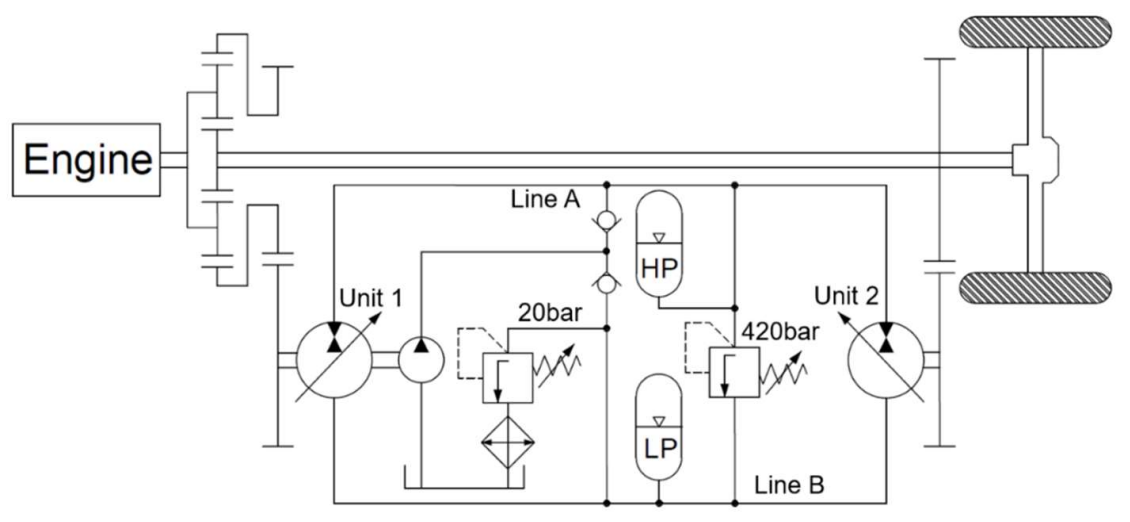

Figure 4. Hydraulic circuit of a power-split HHV. 


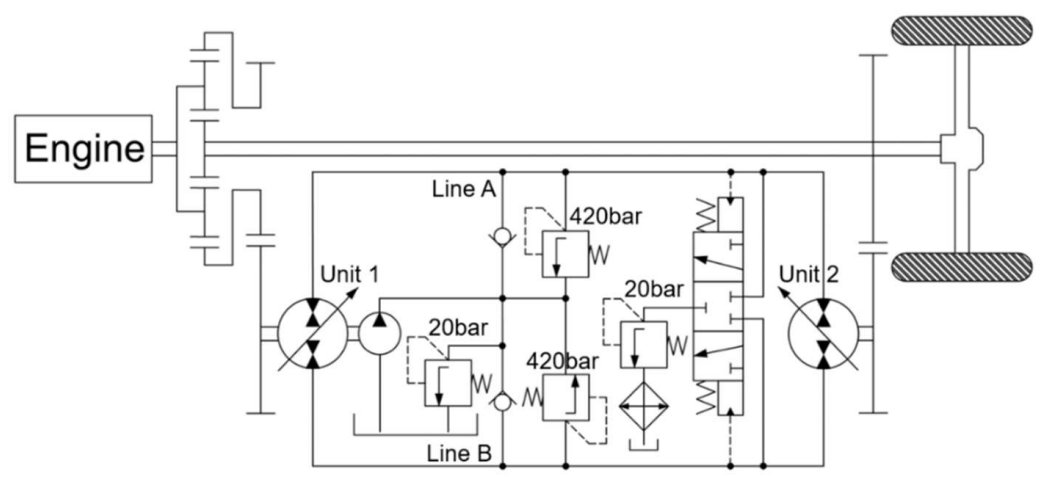

Figure 5. Hydraulic circuit of a power-split HST.

Table 1. System component conditions for power-split HHV and power-split HST.

\begin{tabular}{cc}
\hline Standing Gear Ratio & 1.8 \\
\hline Displacement Volume of Unit-1 & $45 \mathrm{cc}$ \\
\hline Displacement Volume of Unit-2 & $62 \mathrm{cc}$ \\
\hline HP Accumulator Volume & $31.5 \mathrm{~L}$ \\
\hline LP Accumulator Volume & $31.5 \mathrm{~L}$ \\
\hline HP Accumulator Precharge Pressure & $90 \mathrm{bar}$ \\
\hline LP Accumulator Precharge Pressure & $16 \mathrm{bar}$ \\
\hline Maximum System Pressure & $420 \mathrm{bar}$ \\
\hline Low-Pressure Setting & $20 \mathrm{bar}$ \\
\hline
\end{tabular}

Tables 2 and 3 show the principle operating modes for the power-split HHV. There are different principle operating modes for the power-split HHV and the power-split HST. The power-split HHV has additional states compared to the power-split HST due to the existence of hydraulic accumulators. When the vehicle is idle, engine and hydraulic components maintain idle states. For the driving mode, both systems include power-split, full mechanical and recirculation modes. Unit-1 is pumping and Unit-2 is motoring in the power-split mode. When the vehicle drives under the full mechanical mode, both units become idle. For the power recirculation, Unit-1 is motoring and Unit-2 is pumping to deliver recirculation power to the planetary gear train. For power-split HHV, there are three modes under the power-split and power recirculation modes, respectively, since it includes charging and discharging states of the hydraulic accumulator. On the other hand, for power-split HST, only one mode exists for each power-split, full mechanical, and power recirculation modes. When the vehicle is under braking, the engine and Unit- 1 are idle for both systems not to consume energy. For power-split HHV, accumulators charge by the regenerative energy from the wheel. Figures 6 and 7 show the schematics of principle operating modes for the power-split HHV and the power-split HST.

Table 2. Principle modes of operation for power-split HHV.

\begin{tabular}{|c|c|c|c|c|c|c|}
\hline Mode & Engine & Unit-1 & Accumulator & Unit-2 & Driveline & Note \\
\hline 1 & Idle & Idle & Idle & Idle & Idle & - \\
\hline 2 & Motoring & Pumping & Charging & Motoring & Driving & \multirow{3}{*}{ Power Additive } \\
\hline 3 & Motoring & Pumping & Idle & Motoring & Driving & \\
\hline 4 & Motoring & Pumping & Discharging & Motoring & Driving & \\
\hline 5 & Motoring & Idle & Idle & Idle & Driving & Full Mechanical \\
\hline 6 & Motoring & Motoring & Charging & Pumping & Driving & \multirow{3}{*}{ Power Recirculation } \\
\hline 7 & Motoring & Motoring & Idle & Pumping & Driving & \\
\hline 8 & Motoring & Motoring & Discharging & Pumping & Driving & \\
\hline 9 & Idle & Idle & Charging & Pumping & Braking & - \\
\hline
\end{tabular}


Table 3. Principle modes of operation for power-split HST.

\begin{tabular}{cccccc}
\hline Mode & Engine & Unit-1 & Unit-2 & Driveline & Note \\
\hline 1 & Idle & Idle & Idle & Idle & - \\
\hline 2 & Motoring & Pumping & Motoring & Driving & Power Additive \\
\hline 3 & Motoring & Idle & Idle & Driving & Full Mechanical \\
\hline 4 & Motoring & Motoring & Pumping & Driving & Power Recirculation \\
\hline 5 & Idle & Idle & Pumping & Braking & - \\
\hline
\end{tabular}

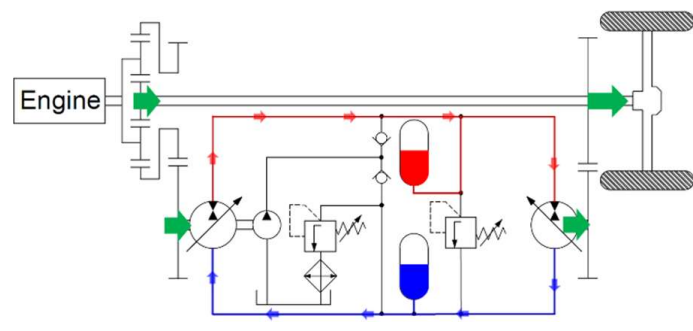

(a) Power Additive Mode

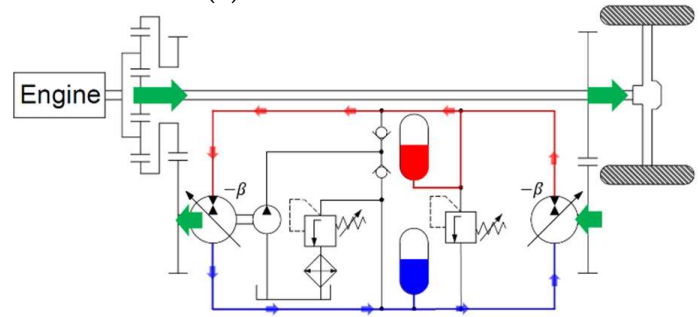

(c) Power Recirculation Mode

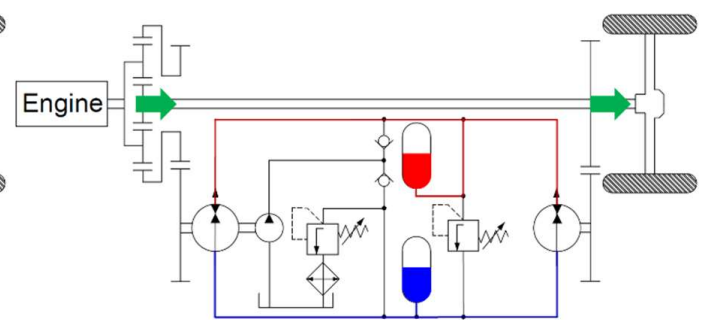

(b) Full Mechanical Mode

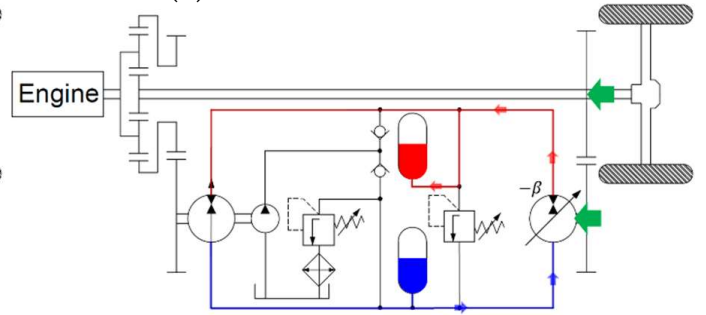

(d) Braking Mode

Figure 6. Schematics of principle operating modes for power-split HHV.

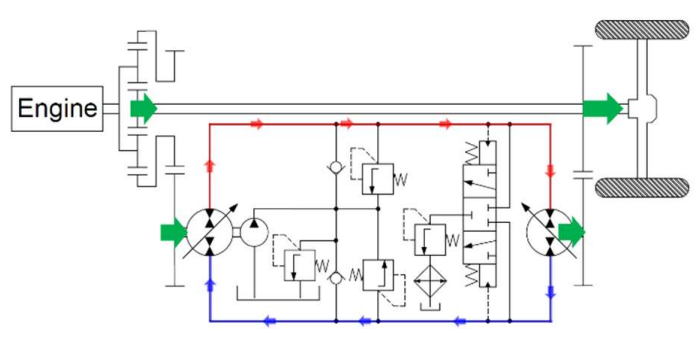

(a) Power Additive Mode

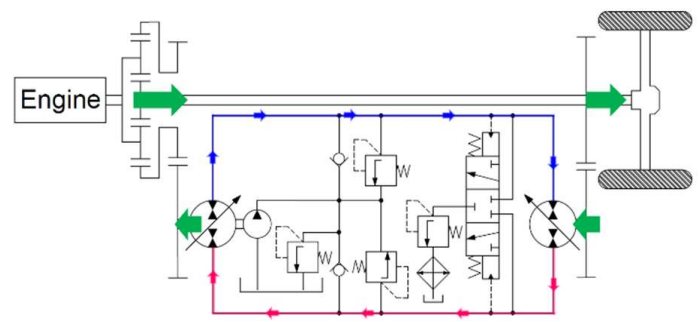

(c) Power Recirculation Mode

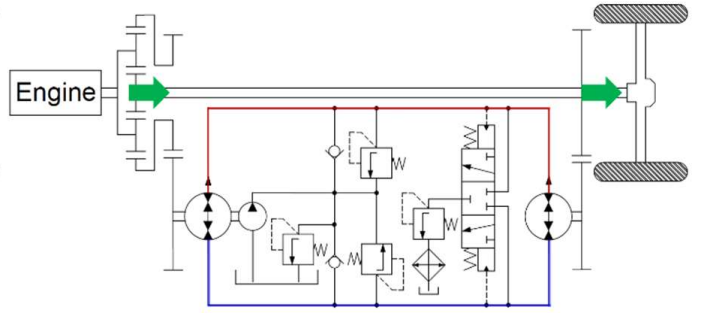

(b) Full Mechanical Mode

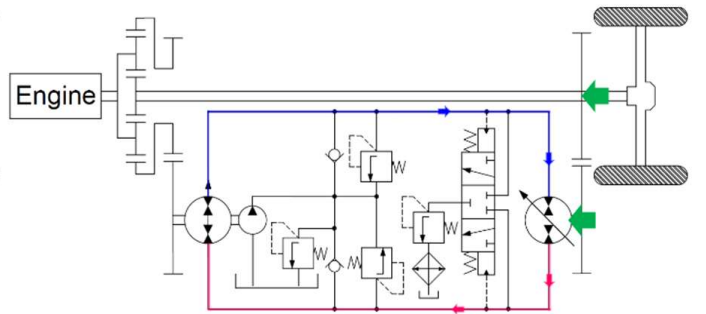

(d) Braking Mode

Figure 7. Schematics of principle operating modes for power-split HST.

\section{Numerical Analysis}

\subsection{Modeling Approach}

The system simulation was organized based on a novel modeling approach which considers dynamical and thermal behaviors proposed in recent studies $[31,33,34]$. Figure 8 shows the block 
diagram for system modeling. First, the overall system dynamics are calculated based on the hydraulic system model together with the engine and vehicles dynamics. The feedback controller utilizes the reference driving cycle and actual vehicle speed with pressure data from the hydraulic system model. The engine speed is assumed as constant like a control strategy for constant-speed diesel engines $[37,38]$. The displacements of hydraulic units are adjusted by PI controllers as input parameters for the hydraulic system model. For thermal modeling, the pressure and flow rate data from the dynamic system model are utilized as input parameters. The output data are finally utilized for analyzing the characteristics of the overall system. The details of vehicle dynamics, system control, hydraulic system model, and thermal model are described in the following sections.

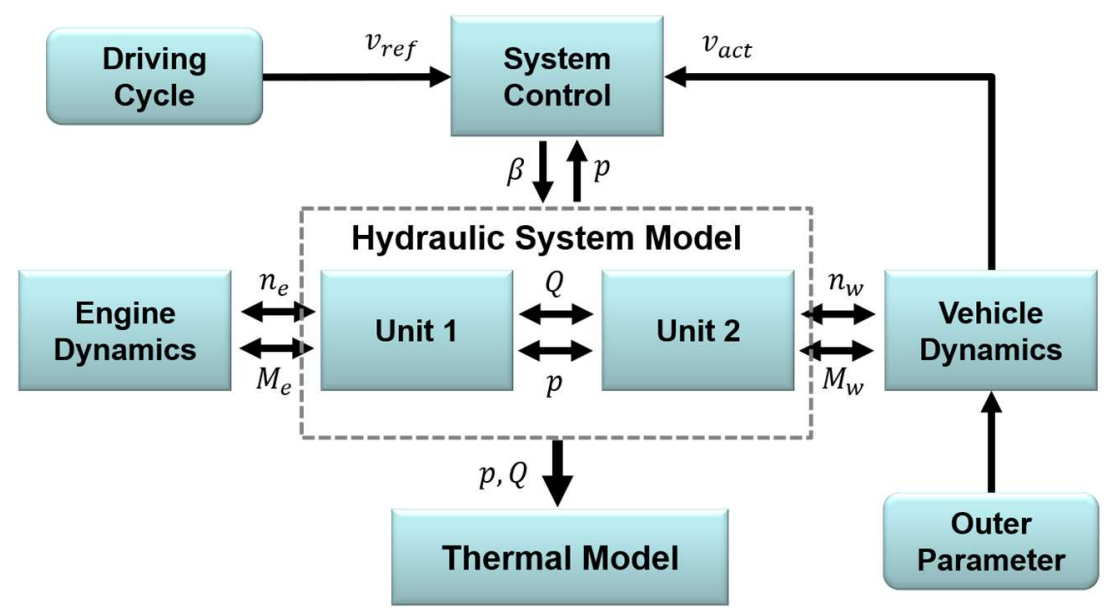

Figure 8. Block diagram for system modeling.

\subsection{Dynamic System Modeling}

The planetary gear train can be modeled based on the lever diagram. Figure 9 shows the lever diagram of the planetary gear train. The angular speed and torque relations can be expressed by the standing gear ratio as follows:

$$
\begin{gathered}
i=\frac{r_{r}}{r_{S}} \\
(1+i) \omega_{C}=\omega_{S}+i \omega_{R} \\
\tau_{S}: \tau_{C}: \tau_{R}=1:-(1+i): i
\end{gathered}
$$

where $i$ is the standing gear ratio, $r_{R}$ is the radius of the ring gear, $r_{S}$ is the radius of the sun gear, $\omega_{S}$ is the angular speed of the sun gear, $\omega_{C}$ is the angular speed of the gear carrier, $\omega_{R}$ is the angular speed of the ring gear, $\tau_{S}$ is the torque on the sun gear, $\tau_{C}$ is the torque on the gear carrier, and $\tau_{R}$ is the torque on the ring gear.
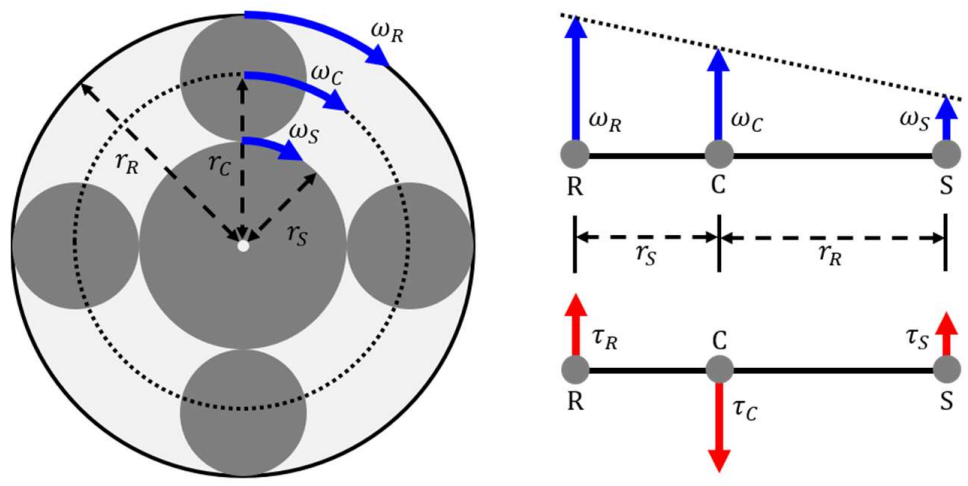

Figure 9. Lever diagram of the planetary gear train. 
The efficiency of the power-split transmission can be estimated with the power ratio of the series and mechanical paths. The power ratio to the series path and efficiency of the power-split transmission can be calculated as follows [10]:

$$
\begin{gathered}
\gamma_{c r}=i+1 \\
\gamma_{s}=\frac{P_{s}}{P_{\text {in }}}=1-\frac{\gamma_{S R}}{\gamma_{c r}} \\
\gamma_{S R}=\frac{\omega_{\text {out }}}{\omega_{\text {in }}} \\
\eta_{T M}=\frac{P_{\text {out }}}{P_{\text {in }}}=\left(1-\frac{P_{s}}{P_{\text {in }}}\right)+\eta_{s} \frac{P_{s}}{P_{\text {in }}}=\left(1-\gamma_{s}\right)+\eta_{s} \gamma_{s}
\end{gathered}
$$

where $\gamma_{c r}$ is the critical speed ratio, $\gamma_{s}$ is the series path power ratio, $P_{S}$ is the power to the series path, $P_{\text {in }}$ is the input power, $\gamma_{S R}$ is the speed ratio, $\omega_{\text {in }}$ is the input speed, $\omega_{\text {out }}$ is the output speed, $\eta_{T M}$ is the efficiency of the power-split transmission, $P_{\text {out }}$ is the output power, and $\eta_{s}$ is the efficiency of the series path. Figure 10 shows the efficiency and power ratio of output-coupled power-split transmission at $\gamma_{c r}=2.8$, which was used in this study for power-split configurations, as shown in Figures 4 and 5 . The power ratio to the series path decreases with an increasing speed ratio and it becomes negative after the full mechanical point due to the power recirculation mode. The efficiency increases when the speed ratio is smaller than the critical speed ratio and decreases after the full mechanical point.

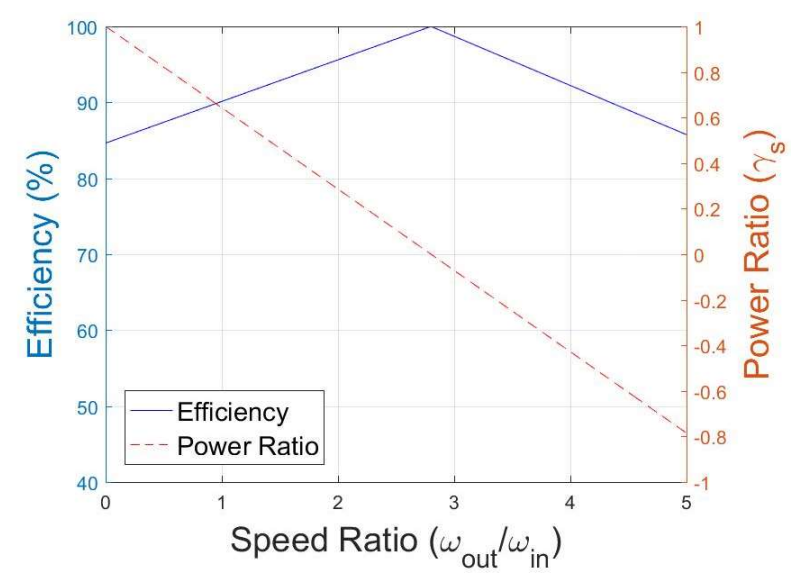

Figure 10. Efficiency and power ratio of output-coupled power-split system.

The vehicle dynamics are modeled based on the force balance equation as follows:

$$
F_{t o t}=F_{t}+F_{g}+F_{r}+F_{D}=m a
$$

where $F_{t o t}$ is the net force applied to the vehicle, $F_{t}$ is the traction force, $F_{g}$ is the gravitational force, $F_{r}$ is the rolling resistance, $F_{D}$ is the aerodynamic drag, $a$ is the acceleration of the vehicle, and $m$ is the mass of the vehicle. The traction force, gravitation force, rolling resistance, and aerodynamic drag are calculated from the following equations:

$$
\begin{gathered}
F_{t}=\frac{M_{w}}{r_{d y n}} \\
F_{g}=-m g \sin \theta \\
F_{r}=-C_{r} \cdot m g \cos \theta \\
F_{D}=-\frac{1}{2} \rho A_{f} C_{d} v^{2}
\end{gathered}
$$


where $M_{w}$ is torque loaded on the wheel, $r_{d y n}$ is the wheel dynamic radius, $g$ is the gravitational acceleration, $\theta$ is the angle of the slope, $C_{r}$ is the rolling resistance coefficient, $\rho$ is the density of the air, $A_{f}$ is the frontal area of the vehicle, $C_{d}$ is the drag coefficient, and $v$ is the speed of the vehicle. Once the acceleration of the vehicle is obtained from the vehicle dynamics model, velocity is obtained by the integral of the acceleration and used as an input to the hydraulic system model.

Different control strategies are applied for the power-split HHV and the power-split HST. Figures 11 and 12 show the control system block diagrams for the power-split HHV and the power-split HST, where $v_{\text {ref }}$ is the reference vehicle speed, $v_{a c t}$ is the actual vehicle speed, $d p_{r e f}$ is the reference pressure difference, $\beta_{1}$ is the displacement of Unit-1, $\beta_{2}$ is the displacement of Unit-2, $d p$ is the pressure difference, and $M_{w}$ is the wheel torque. For the power-split HHV, secondary control is applied to determine the displacements of hydraulic units. In the secondary control, while the displacement of Unit-2 is determined only by the velocity signal, the displacement of Unit- 1 is decided by system reference pressure as well as the velocity signal. For the power-split HST, sequential control is utilized, which determines the displacements of both units with the velocity signal. During braking for both systems, the displacement of Unit-1 becomes zero for preventing energy from the engine and the displacement of Unit-2 is adjusted according to the required braking torque for the reference driving cycle.

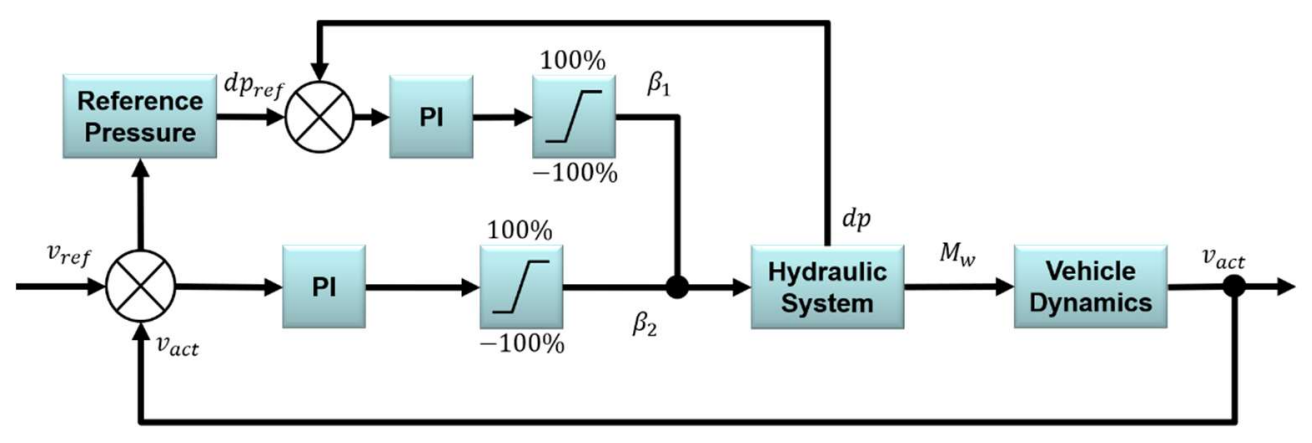

Figure 11. Control system block diagram for power-split HHV.

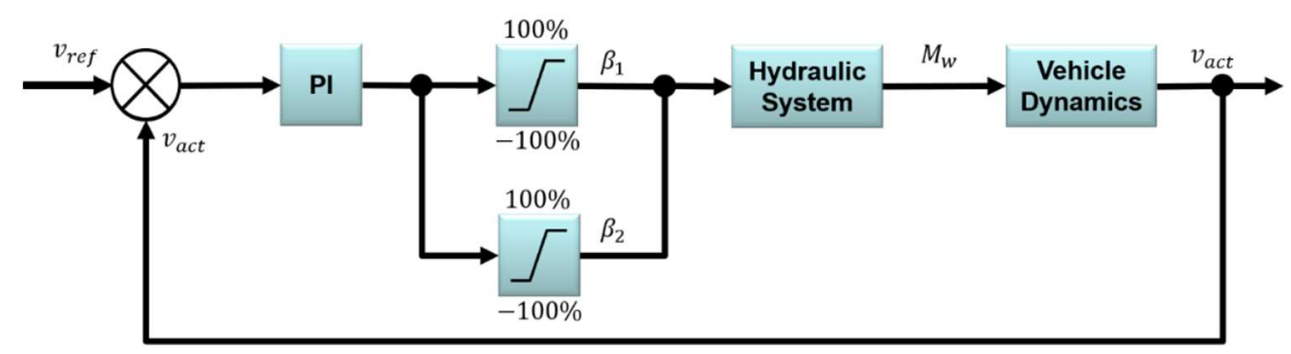

Figure 12. Control system block diagram for power-split HST.

\subsection{Hydraulic System Modeling}

The hydraulic systems of both power-split configurations were analyzed based on the lumped parameter due to its merits for system scale analysis. Governing equations for hydraulic components are described analytically with empirical models for loss characteristics of hydraulic units. The displacements of hydraulic units, determined by system control are utilized as input parameters of the hydraulic systems. The outputs like pressure and flow rate of the overall system were analyzed for analysis of power-split HHV, which were also used as input parameters for thermal modeling.

For the hydraulic units, the theoretical flow rate can be calculated with the unit speed and derived displacement as follows:

$$
Q_{i}=n \beta V_{i}
$$


where $Q_{i}$ is the theoretical flow rate, $n$ is the speed of the unit, $\beta$ is the adjusted displacement of the unit normalized to the maximum displacement, and $V_{i}$ is the derived displacement volume. Theoretical torque $M_{i}$ can be obtained from the following equation:

$$
M_{i}=\beta V_{i} \Delta p
$$

where $\Delta p$ is the differential pressure between the inlet and outlet ports.

Theoretical flow rate and theoretical torque are used for calculating the effective flow rate and effective torque. Figure 13 shows the schematics of the loss behavior for hydraulic units. When the hydraulic unit of the positive displacement machine works as a pump, effective flow rate and effective torque can be calculated as [39]:

$$
\begin{gathered}
Q_{e}=Q_{i}-Q_{s}=Q_{i}-\left(Q_{s i}+Q_{s e}\right) \\
M_{e}=M_{i}+M_{s}
\end{gathered}
$$

where $Q_{e}$ is the effective flow rate, $Q_{s}$ is the volumetric loss, $Q_{s i}$ is the internal volumetric loss, $Q_{s e}$ is the external volumetric loss, $M_{e}$ is the effective torque, and $M_{s}$ is the torque loss. For motoring, the hydraulic unit can be described as follows:

$$
\begin{gathered}
Q_{e}=Q_{i}+Q_{s}=Q_{i}+\left(Q_{s i}+Q_{s e}\right) \\
M_{e}=M_{i}-M_{s}
\end{gathered}
$$

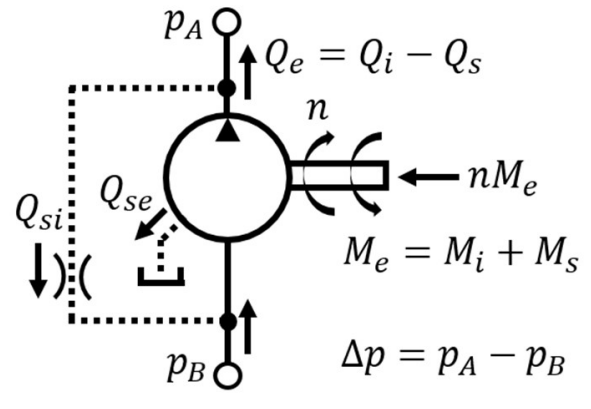

(a) Pumping

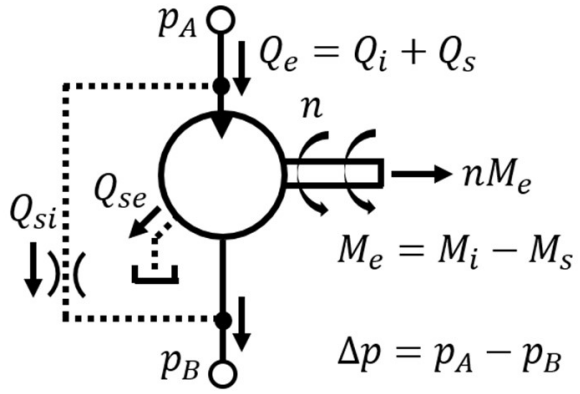

(b) Motoring

Figure 13. Schematics of the loss behavior for hydraulic units.

The volumetric loss and torque loss of the hydraulic units can be modeled through an empirical loss model, which is based on experimentally measured data utilizing steady state measurement according to ISO standard. Figure 14 shows the empirical loss model for a hydraulic unit for volumetric efficiency and torque efficiency. The loss model was generated based on a positive displacement axial piston hydraulic unit of $75 \mathrm{cc}$ and it was applied for each hydraulic unit model by a scaling law [40]. Loss power was dissipated as heat and the temperatures of the fluid and the ports of hydraulic unit increase. The energy dissipation and heat generation were considered for thermal modeling with energy balance equations.

The summation of the inlet and outlet flows of the hydraulic line builds the pressure of the hydraulic line. The pressure rate balance of the hydraulic line can be obtained from the pressure build-up equation as follows [41]:

$$
\dot{p}=\frac{1}{C_{h}}\left(\sum Q_{\text {in }}-Q_{o u t}+\frac{d V}{d t}\right)
$$


where $\dot{p}$ is the pressure variation rate, $C_{h}$ is the hydraulic capacitance, and $Q_{i n}$ and $Q_{o u t}$ are the flow rates in and out of the control volume, respectively.

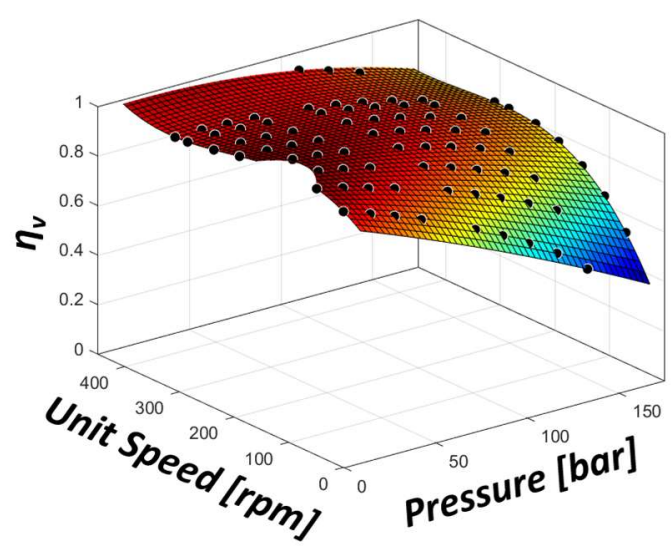

(a) Volumetric efficiency

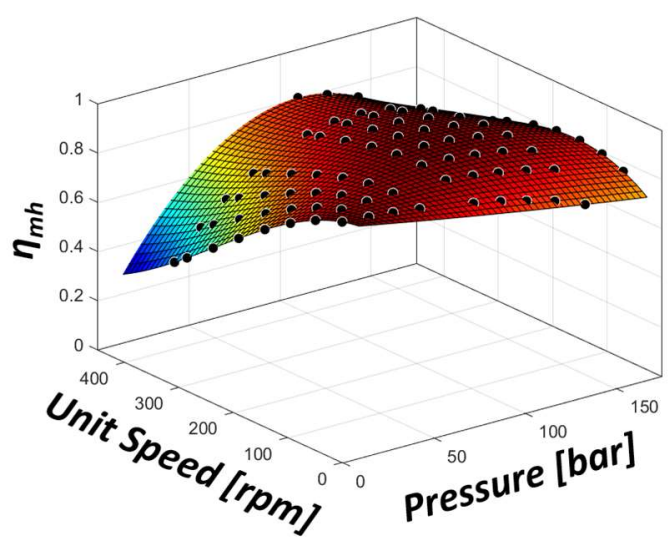

(b) Torque efficiency

Figure 14. Empirical loss model for a hydraulic unit for (a) volumetric efficiency and (b) torque efficiency.

The hydraulic capacitance for the hydraulic line is determined by the following hydraulic capacitance term:

$$
C_{h, \text { line }}=\frac{V}{K}
$$

where $C_{h, l i n e}$ is the hydraulic capacitance for the hydraulic line, $V$ is the control volume, and $K$ is the bulk modulus of the hydraulic oil. The hydraulic capacitance of the accumulator can be derived based on a polytropic process assumption. The hydraulic capacitance in the accumulator is obtained from the polytropic process equation as follows:

$$
C_{h, a c c}=\frac{V_{0}}{n}\left(\frac{p_{0}}{p^{n+1}}\right)^{\frac{1}{n}}
$$

where $C_{h, a c c}$ is the hydraulic capacitance for the accumulator, $V_{0}$ is the initial gas volume, $n$ is the polytropic coefficient, $p_{0}$ is the precharge pressure, and $p$ is the current system pressure.

The flow through valves in the system can be modeled by the orifice equation. For pressure relief valves, valves open once the inlet pressure exceeds the valve's set pressure. The flow through a relief valve can be calculated as follows:

$$
Q_{\text {relief }}= \begin{cases}C_{\text {relief }} \sqrt{p-p_{\text {relief }}} & \text { for } p-p_{\text {relief }}>0 \\ 0 & \text { for otherwise }\end{cases}
$$

where $Q_{\text {relief }}$ is the flow rate through the pressure relief valve, $C_{\text {relief }}$ is the coefficient for the pressure relief valve, $p$ is the pressure before the pressure relief valve, and $p_{\text {relief }}$ is the pressure after the pressure relief valve. Check valves can also be modeled with the orifice equation as follows:

$$
Q_{\text {check }}= \begin{cases}C_{\text {check }} \sqrt{p_{\text {check }}-p} & \text { for } p_{\text {check }}-p>0 \\ 0 & \text { for otherwise }\end{cases}
$$

where $Q_{\text {check }}$ is the flow rate through the check valve, $C_{\text {check }}$ is the coefficient for the check valve, $p_{\text {check }}$ is the pressure before the check valve, and $p$ is the pressure after the check valve. 


\subsection{Thermal Modeling}

The system temperature was predicted by thermal modeling based on the lumped parameter model. The energy rate balance of each component is determined with the first law of thermodynamics. The overall hydraulic system was separated into several control volumes and the temperature of each control volume was calculated with equations of the energy rate balance. For the modeling, nitrogen gas inside the accumulator is considered as adiabatically insulated from hydraulic oil. The heat generated outside of the hydraulic system such as the engine and mechanical shaft was not considered in the modeling and the measured ambient air temperature is used as a boundary condition.

The governing equation can be obtained from the first law of thermodynamics in the unsteady state, without kinetic and potential energy variation. The enthalpy rate balance can be derived as follows:

$$
\frac{d h}{d t}=\frac{1}{\rho V}\left[\dot{\varphi}-\dot{W}_{C V}+\dot{m}_{i} h_{i}-\dot{m}_{e} h_{e}-V h \frac{d \rho}{d t}-(\rho h-p) \frac{d V}{d t}+V \frac{d p}{d t}\right]
$$

where $h$ is the specific enthalpy, $\rho$ is the density, $\varphi$ is the heat, $W_{C V}$ is the work done by control volume, and the dot on the parameter means the derivates of the variable with respect to time. The enthalpy rate balance can be expressed as a partial differential equation of density and temperature as follows:

$$
\frac{d h}{d t}=\left.\frac{\partial h}{\partial p}\right|_{T} \frac{d p}{d t}+\left.\frac{\partial h}{\partial T}\right|_{p} \frac{d T}{d t}
$$

The terms in Equation (25) can be expressed as

$$
\begin{gathered}
\left.\frac{\partial h}{\partial p}\right|_{T}=\frac{1}{\rho}-\beta_{T} T v \\
\left.\frac{\partial h}{\partial T}\right|_{p}=c_{p}
\end{gathered}
$$

where $\beta_{T}$ is the volumetric thermal expansion coefficient, $v$ is the specific volume, and $c_{p}$ is the isobaric specific heat capacity. The temperature rata balance can be derived with the constitute equations as follows:

$$
\frac{d T}{d t}=\frac{1}{c_{p} \rho V}\left[\dot{\varphi}-\dot{W}_{C V}+\dot{m}_{i} h_{i}-\dot{m}_{e} h_{e}-h\left(\dot{m}_{i}-\dot{m}_{e}\right)+p \frac{d V}{d t}+\beta_{T} T V \frac{d p}{d t}\right]
$$

The pressure rate balance can be expressed with the bulk modulus and volumetric thermal expansion coefficient as follows:

$$
\frac{d p}{d t}=\frac{K}{\rho V}\left(\dot{m}_{i}-\dot{m}_{e}-\rho \frac{d V}{d t}\right)+\beta_{T} K \frac{\partial T}{d t}
$$

where $K$ is the bulk modulus. The pressure rate balance in Equation (28) can be replaced with Equation (29), and therefore, the governing equation for thermal modeling can finally be organized as follows:

$$
\frac{d T}{d t}=\frac{1}{V\left(c_{p} \rho-\beta_{T}^{2} K T\right)}\left[\dot{\varphi}-\dot{W}_{C V}+\dot{m}_{i} h_{i}-\dot{m}_{e} h_{e}+\left(\frac{\beta_{T} K T}{\rho}-h\right)\left(\dot{m}_{i}-\dot{m}_{e}\right)+\left(p-\beta_{T} K T\right) \frac{d V}{d t}\right]
$$

The governing equation can be simplified differently for each hydraulic component for thermal modeling with different assumptions and operating conditions. Hydraulic pumps and motors are the main heat sources of the hydraulic system and the heat is generated due to the power losses occurring within the real working process of the pump or motor. The internal energy of the hydraulic unit is 
increased according to the power losses during energy transfer and the increase of internal energy induces temperature increasing. The temperature rate balance for hydraulic units becomes:

$$
\frac{d T}{d t}=\frac{1}{V\left(c_{p} \rho-\beta_{T}^{2} K T\right)}\left[\dot{\varphi}-\dot{W}_{C V}+\dot{m}_{i} h_{i}-\dot{m}_{e} h_{e}+\left(\frac{\beta_{T} K T}{\rho}-h\right)\left(\dot{m}_{i}-\dot{m}_{e}\right)\right]
$$

For the hydraulic units, the work term expresses the mechanical shaft work, which can be calculated by flow rate and differential flow as follows:

$$
\dot{W}_{s}=Q \Delta p
$$

where $W_{s}$ is the shaft work in the hydraulic unit.

In the hydraulic accumulators, the energy is stored in the compressed gas through the volumetric work. The work term in the governing equation expresses volumetric work by the moving boundaries, which can be calculated by the pressure and the derivative of the volume with respect to time as follows:

$$
\dot{W}_{v}=p \frac{d V}{d t}
$$

where $W_{v}$ is the volumetric work done by the accumulator. The temperature rate balance for hydraulic accumulators can be obtained as follows:

$$
\frac{d T}{d t}=\frac{1}{V\left(c_{p} \rho-\beta_{T}^{2} K T\right)}\left[\dot{\varphi}+\dot{m}_{i} h_{i}-\dot{m}_{e} h_{e}-h\left(\dot{m}_{i}-\dot{m}_{e}\right)+\frac{\beta_{T} K T}{\rho} V \frac{d \rho}{d t}\right]
$$

For the hydraulic lines, the temperature rata balance, assuming that there is no volume change and work done by the control volume, becomes

$$
\frac{d T}{d t}=\frac{1}{V\left(c_{p} \rho-\beta_{T}^{2} K T\right)}\left[\dot{\varphi}+\dot{m}_{i} h_{i}-\dot{m}_{e} h_{e}+\left(\frac{\beta_{T} K T}{\rho}-h\right)\left(\dot{m}_{i}-\dot{m}_{e}\right)\right]
$$

For the reservoir, the pressure and volume can be assumed as constant. The temperature in the reservoir can be predicted with the temperature rata balance as follows:

$$
\frac{d T}{d t}=\frac{1}{c_{p} \rho V}\left[\dot{\varphi}+\dot{m}_{i} h_{i}-\dot{m}_{e} h_{e}-h\left(\dot{m}_{i}-\dot{m}_{e}\right)\right]
$$

Coolers were utilized for managing the system temperature of the hydraulic system. For the cooler, the heat transfer was predicted by a function of the flow rate through the cooler since it is difficult to predict the nonlinear behavior of the heat transfer by using the lumped parameter model due to its complex geometry. It was assumed that the heat transfer coefficient is a function of the flow rate as follows:

$$
k_{\text {cooler }}=f\left(Q_{\text {cooler }}\right)
$$

where $k_{\text {cooler }}$ is the heat transfer coefficient of the cooler, $Q_{\text {cooler }}$ is the flow rate of hydraulic oil through the cooler. The function can be assumed based on the empirical data for the cooling capacitance of the coolers from the manufacturers. Figure 15 shows the cooling performance curve of the cooler used in this study, where $\phi_{\text {cooling }}$ is the cooling capacity of the cooler.

The term for heat release in the governing equation can be calculated from the heat transfer relations. The heat transfer coefficient between hydraulic oil and ambient air can be determined by a lumped parameter model for heat transfer as follows:

$$
\dot{\varphi}=\frac{\Delta T}{R_{e q}}
$$




$$
\begin{gathered}
R_{\text {eq }}=R_{1}+R_{2}+R_{3} \\
R_{1}=\frac{1}{h_{\text {in }} A_{\text {in }}} \\
R_{2}=\frac{\ln \left(\frac{d_{0}}{d_{i}}\right)}{2 \pi l_{\text {pipe }} k} \\
R_{3}=\left(\frac{1}{h_{\text {out }}+h_{\text {rad }}}\right) \frac{1}{A_{\text {out }}}
\end{gathered}
$$

where $R_{e q}$ is the total equivalent thermal resistance between the hydraulic oil and ambient air, $R_{1}$ is the thermal resistance between the hydraulic oil and the inside of the wall, $R_{2}$ is the thermal resistance between the inside and outside of the wall, $R_{3}$ is the thermal resistance between the outside wall and ambient air, $h_{\text {in }}$ is the convection coefficient of the inside wall, $A_{\text {in }}$ is the area of the inside wall, $d_{0}$ is the diameter to the outside wall, $d_{i}$ is the diameter to the inside wall, $l_{\text {pipe }}$ is the length of the pipe, $k$ is the thermal conductivity of the wall, $h_{\text {out }}$ is the convection coefficient of the outside wall, $h_{\text {rad }}$ is the radiation coefficient of the outside wall, and $A_{\text {out }}$ is the area of the outside wall. The thermal conductivity of steel is used for wall conductivity.

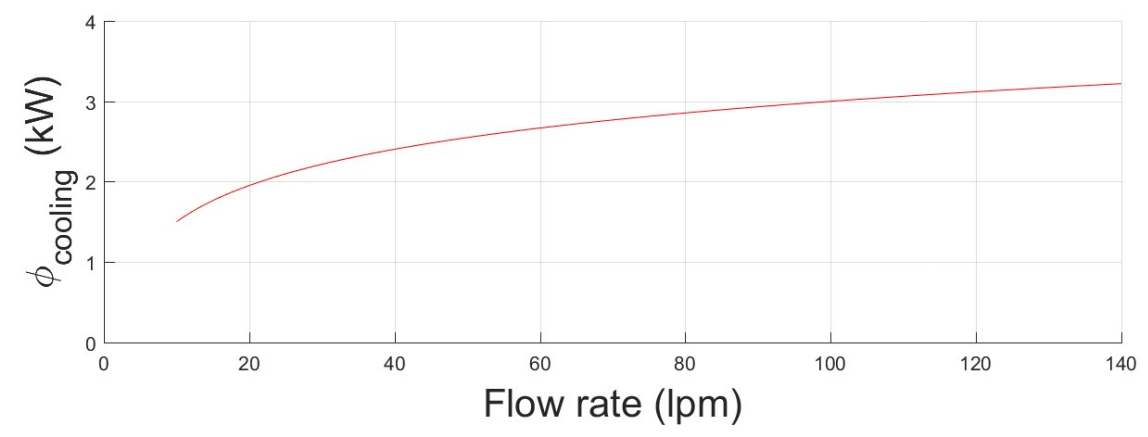

Figure 15. Cooling performance curve of the cooler $\left(\Delta \mathrm{T}=10^{\circ} \mathrm{C}\right)$.

Nusselt number needs to be calculated for determining convection coefficients. Table 4 shows the equations for Nusselt number to calculate the convection coefficients [42-45]. The dimensionless numbers in Table 4 can be defined as follows:

$$
\begin{gathered}
N u=\frac{h L}{k} \\
\operatorname{Re}=\frac{\rho u L}{\mu} \\
\operatorname{Pr}=\frac{c_{p} \mu}{k} \\
G r=\frac{g \beta\left(T_{s}-T_{\infty}\right) L^{3}}{v^{2}}
\end{gathered}
$$

where $N u$ is the Nusselt number, $R e$ is the Reynolds number, $P r$ is the Prandtl number, and $G r$ is the Grashof number. Convection for the inside wall is considered as a forced convection process, and the flow is assumed transitioning to the turbulent flow when the Reynolds number is 2300 . The convection for the outside wall is considered as a free convection process and the geometries of components are assumed as simple such as cylinder and cubic.

Properties of the HLP32 hydraulic oil, such as enthalpy, density, specific heat, thermal conductivity, kinematic viscosity, and bulk modulus can be calculated based on references [46,47]. Thermal properties of materials like steel and air used in this research are obtained from reference [48]. 
Table 4. Equations for Nusselt number for convection coefficients.

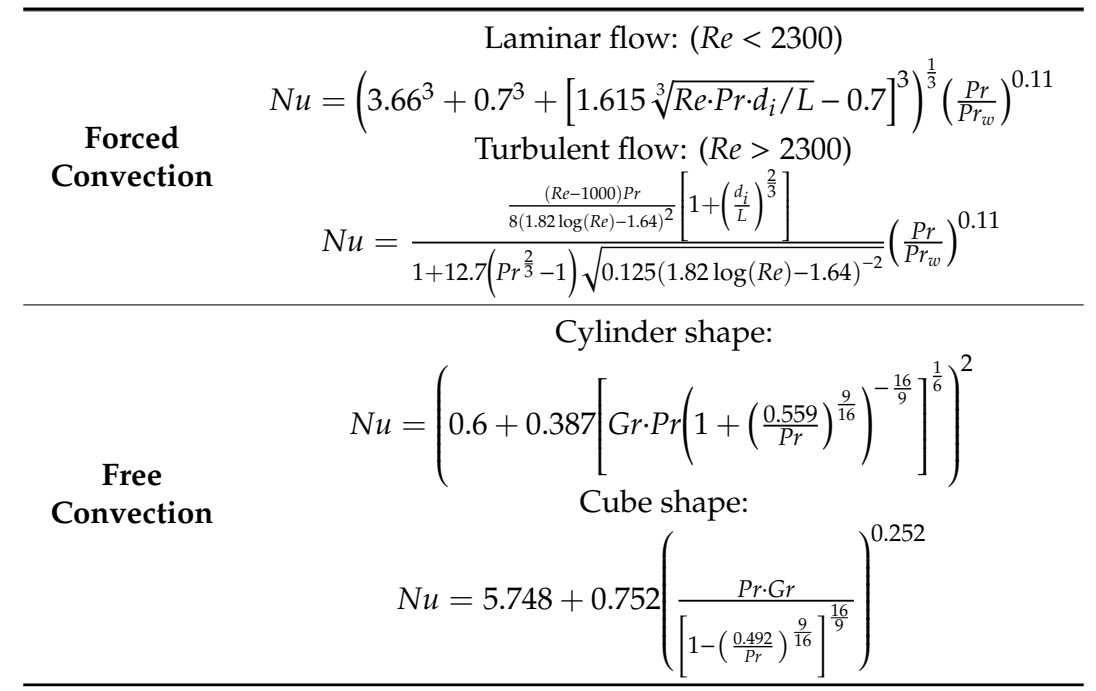

Figures 16 and 17 show the control volumes of the power-split HHV and the power-split HST for thermal modeling. The control volumes include main components of the hydraulic system, such as hydraulic units, hydraulic accumulators, hydraulic lines, cooler, and reservoir. The direction relations of flows between hydraulic components are represented by arrows. In the simulation, the temperature of each control volume is updated every time step with the governing equation of temperature rata balance.

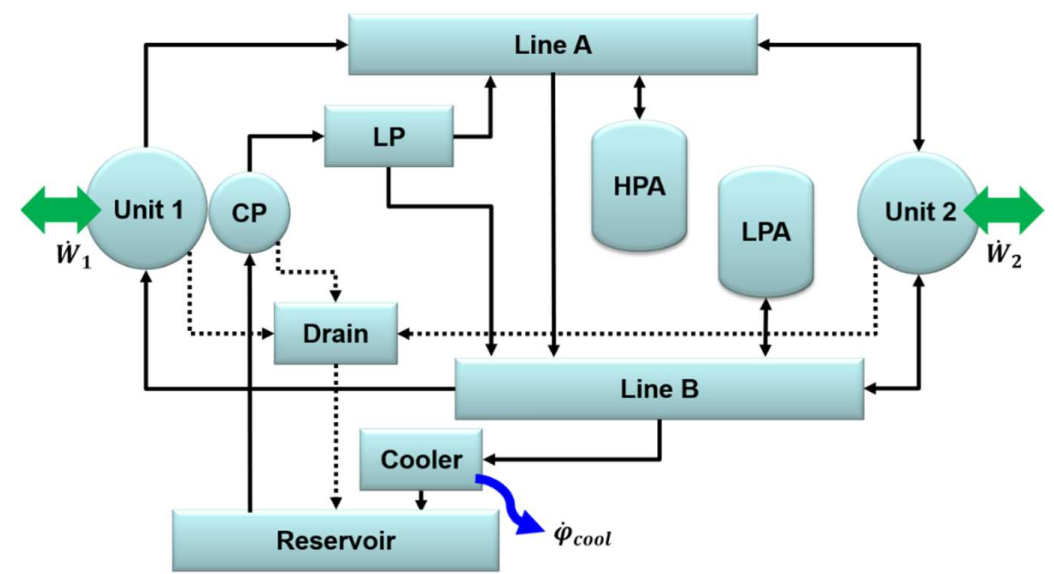

Figure 16. Control volumes of the power-split HHV for thermal modeling.

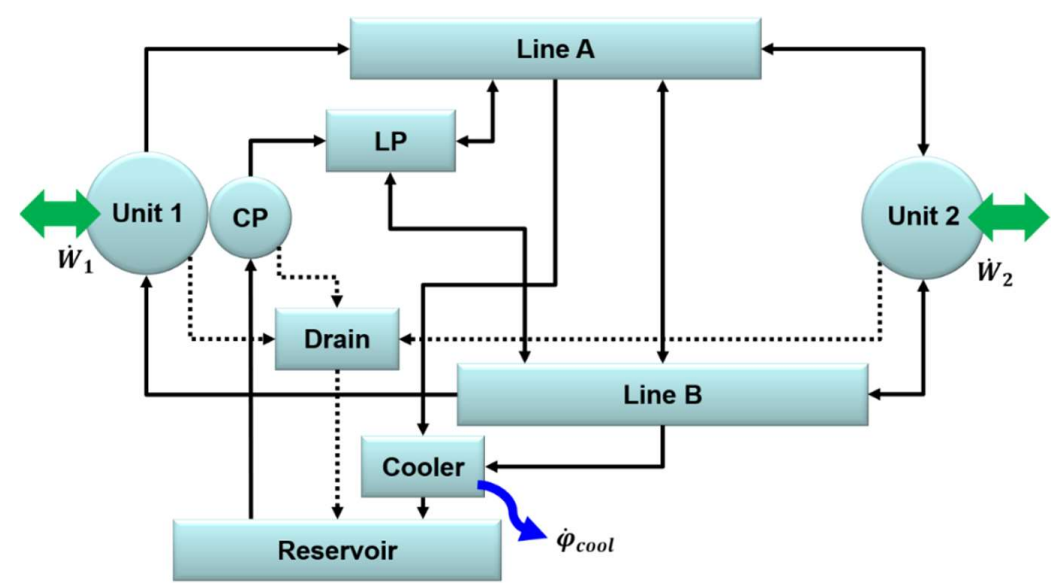

Figure 17. Control volumes of the power-split HST for thermal modeling. 


\section{Results and Discussion}

The power-split hydraulic systems were simulated by Simulink and MATLAB with the FTP-72 driving cycle, also known as the UDDS driving cycle, which is a representative urban driving cycle. Figure 18 shows the velocity profile for the power-split HHV and power-split HST. The velocity results agree well with the reference velocity profile for both power-split transmissions.

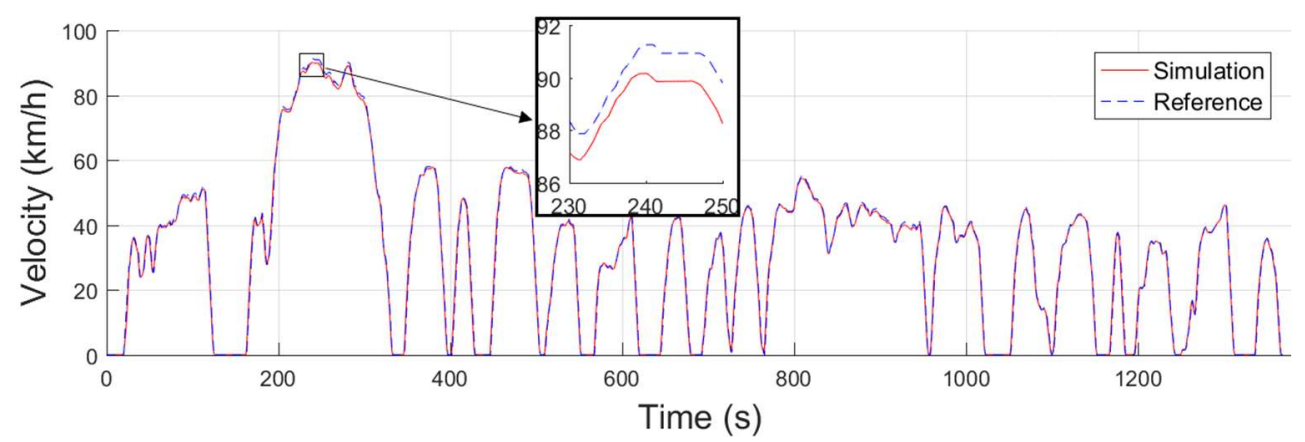

(a)

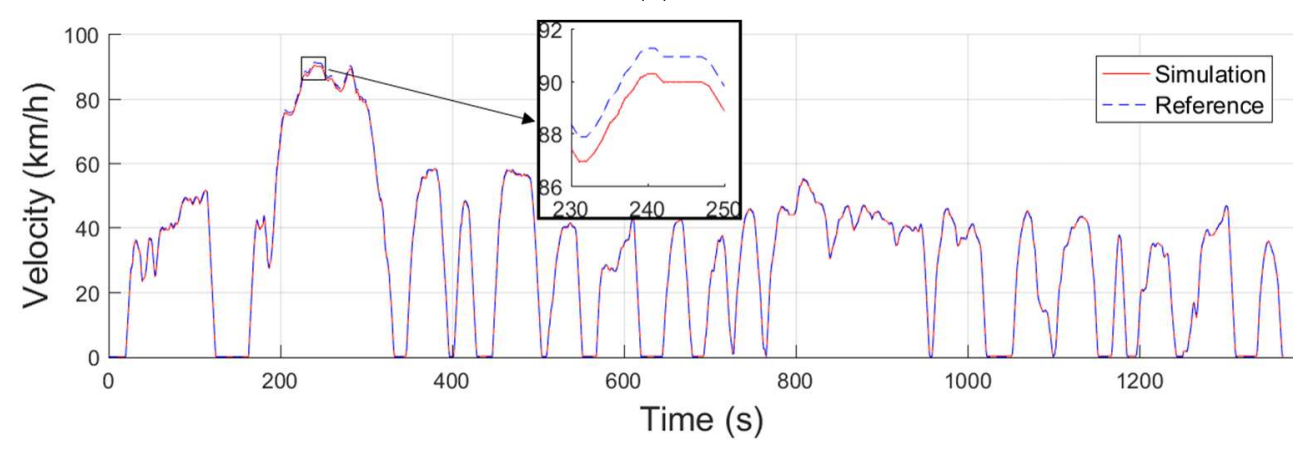

(b)

Figure 18. Velocity profile for (a) power-split HHV and (b) power-split HST.

Figure 19 shows the torque on the planetary gear train for the power-split HHV and the power-split HST. Since torques on ring gear, gear carrier and sun gear of the planetary gear train are related to each other by the torque relation in Equation (3), no torque is loaded on the planetary gear train when the engine is idle with zero torque. According to the results, the torques on the planetary gear train for the power-split HHV has more idle states compared to that for the power-split HST. It shows that the power-split HHV has a possibility to have more engine idling time, which is directly related to more change of engine-off for saving fuel consumption.

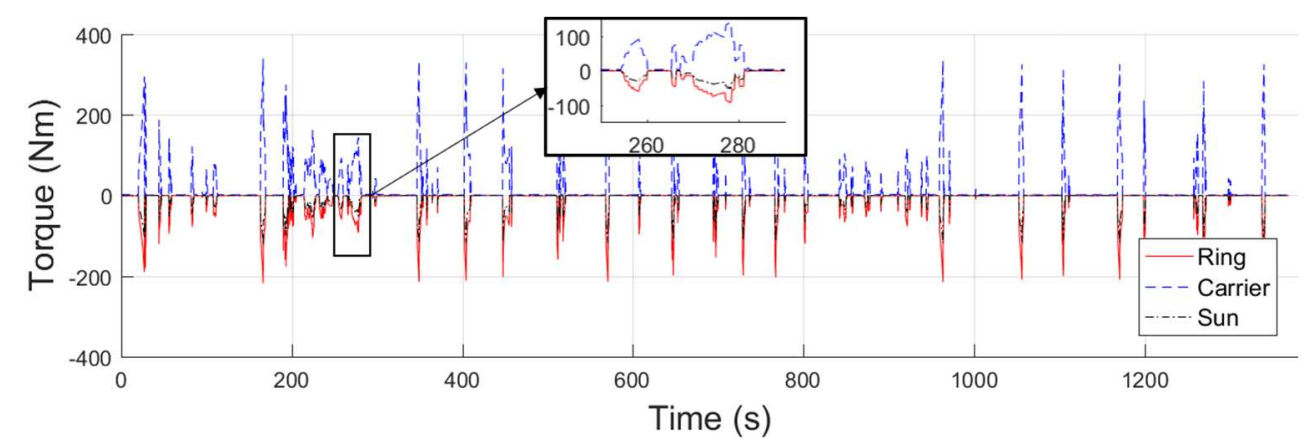

(a)

Figure 19. Cont. 


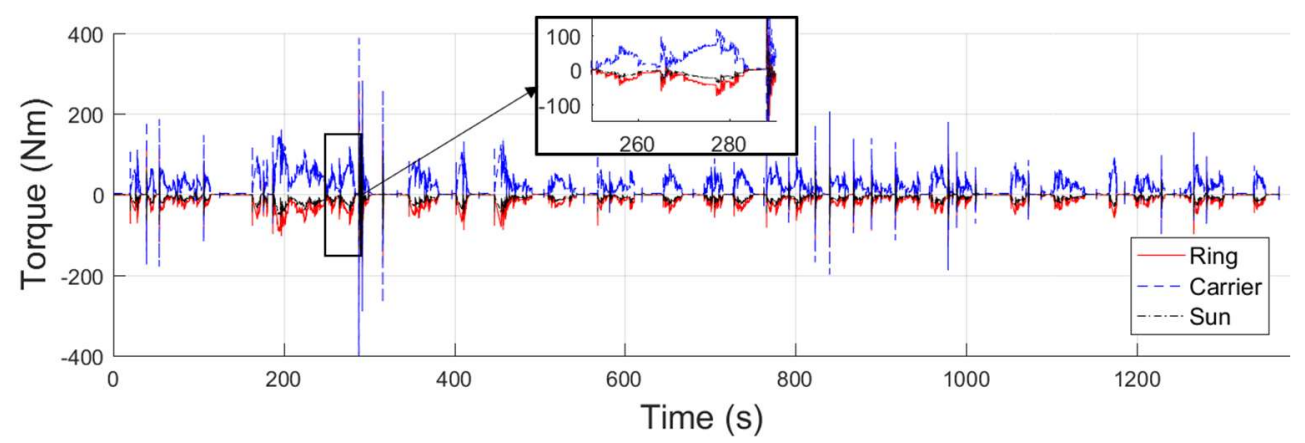

(b)

Figure 19. Torque on the planetary gear train for (a) power-split HHV and (b) power-split HST.

Engine torque was analyzed to observe the energy consumption characteristics of both systems as in Figure 20. The results demonstrate that the power-split HHV has 1.8 times more engine idle time than the power-split HST. Even though the power-split HHV has much more engine idle time, the total engine power consumption of the power-split HHV is $8.2 \%$ less, since more torque is spent when the engine is running. More system idle time offers the possibility of reducing fuel consumption by managing engine operations as follows. First, the engine can stop during idle time with a proper driving condition, which prevents fuel waste due to idle power. Secondly, the engine has a greater possibility of operating efficiently within the optimal operating area of the engine brake system fuel consumption (BSFC) map based on the load leveling strategy, which adjusts torque according to the state of charge of the energy storage. These power-split HHVs characteristics show the clear benefits in terms of energy management and they can be used for designing and organizing the system control logic while developing power-split HHVs.

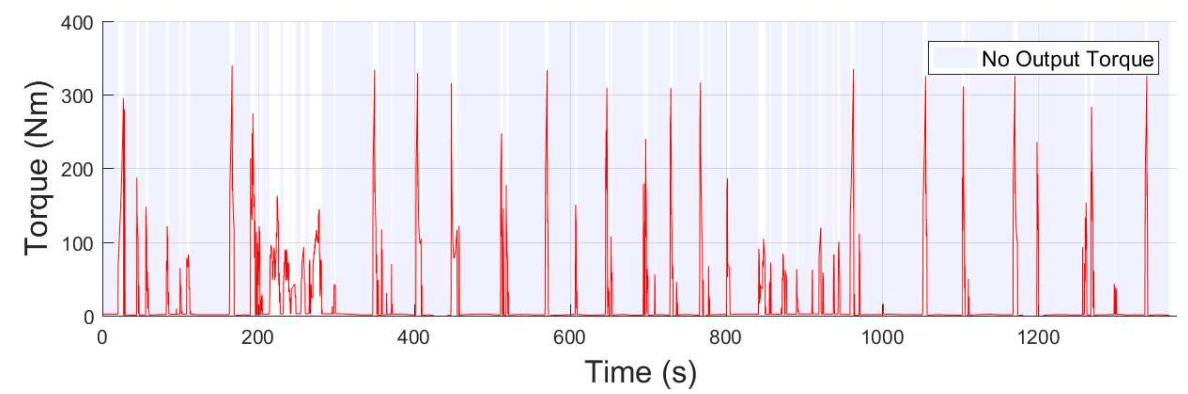

(a)

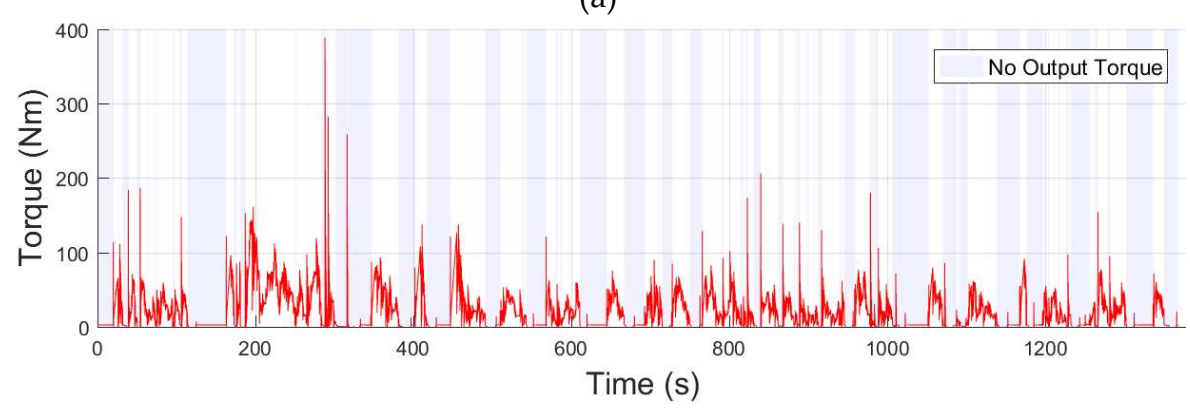

(b)

Figure 20. Engine torque for (a) power-split HHV and (b) power-split HST.

The hydraulic system was analyzed based on the displacements of hydraulic units and the line pressure of both systems. Figure 21 shows the displacements of Unit-1 and Unit-2 for the power-split HHV and the power-split HST. During driving, the displacements of both units for the power-split HHV are adjusted together by the secondary control to match the reference pressure as well as 
the demand torque on the system. For power-split HST, the system is controlled by the sequential control, which adjusts the displacement of Unit-1 first with full displacement of Unit-2 and then, reduces the displacement of Unit-2 when Unit-1 becomes full displacement. While braking, Unit-1 becomes zero displacement, and the system pressure is adjusted by Unit-2 to match the demand torque. The displacement of Unit-2 for the power-split HHV becomes negative to make inverse torque, while that for the power-split HST switches the high-pressure line from Line A to Line B with maintaining positive displacement. Figure 22 shows the line pressure for the power-split HHV and the power-split HST. Line A for the power-split HHV keeps the high-pressure line during the overall driving cycle due to the high-pressure accumulator in Line A. For the power-split HST, line pressure changes according to operating conditions.

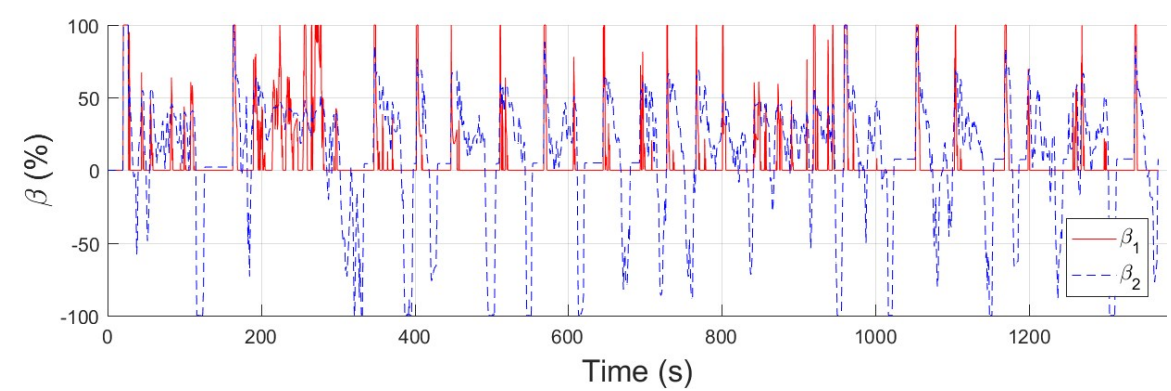

(a)

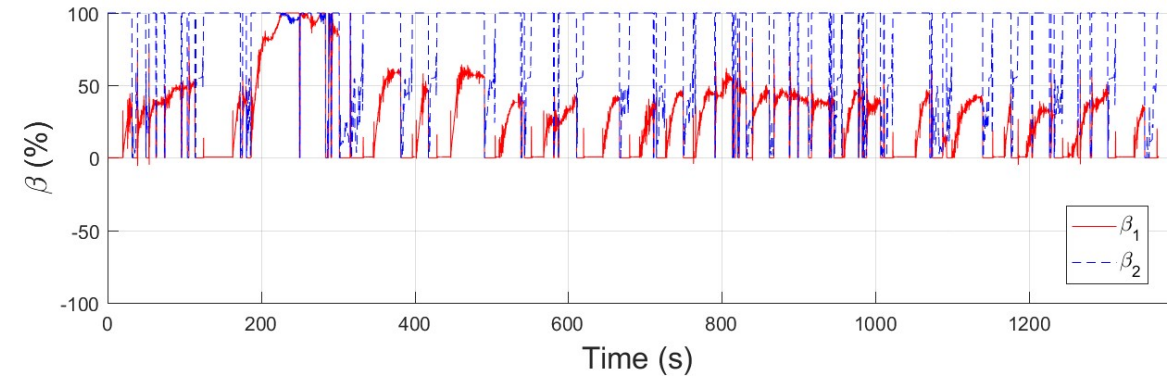

(b)

Figure 21. Displacements of hydraulic units for (a) power-split HHV and (b) power-split HST.

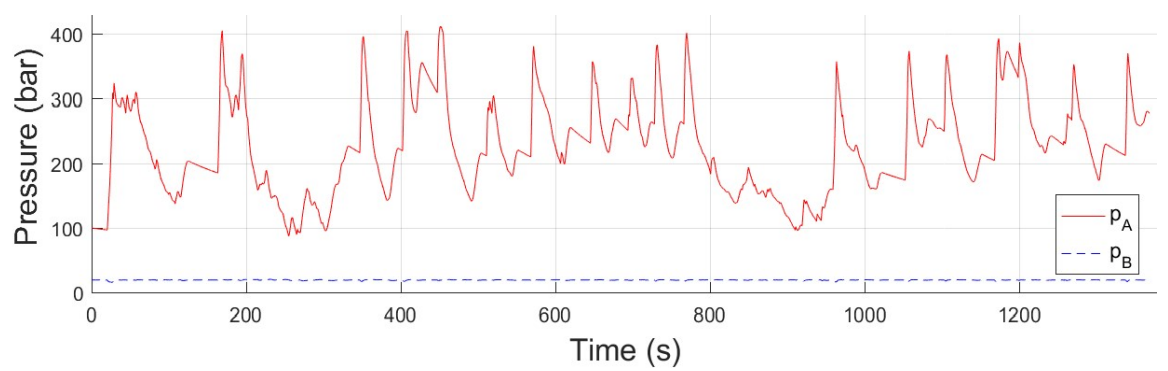

(a)

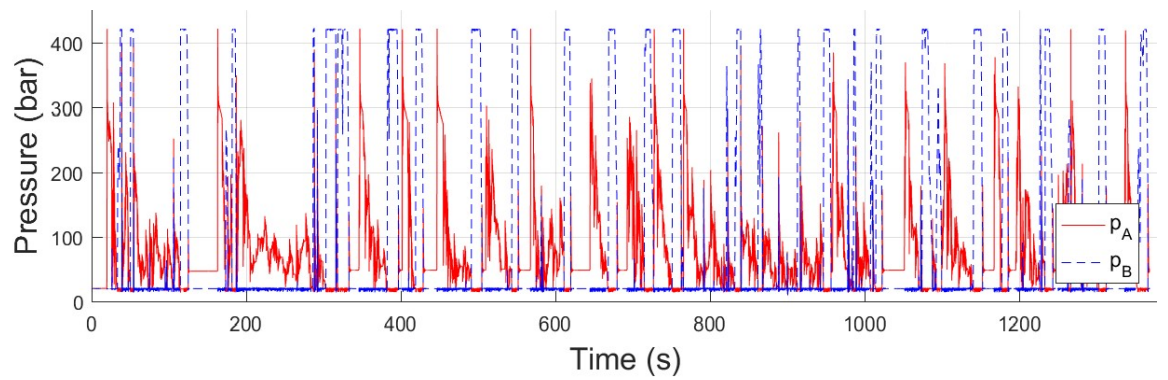

(b)

Figure 22. Line pressure for (a) power-split HHV and (b) power-split HST. 
The system temperature was predicted based on the temperature of the main lines. The analysis of thermal characteristics for the power-split HHVs is crucial because it is not only related to thermal management, which of hydraulic systems is more sensitive compared to other power systems, but it also affects the energy consumption of the overall system. Figure 23 shows the line temperature without cooling for the power-split HHV and the power-split HST. The temperature of Line A for the power-split HHV changes rapidly compared to Line B due to large pressure variation, while the overall trends of temperature variations are similar. The maximum temperature of power-split HST is higher than that for the power-split HHV since most of the braking energy from the wheel is absorbed by the hydraulic system and dissipated as heat. On the other hand, the power-split HHV dissipates less energy by storing the regenerative energy from the wheel in the hydraulic accumulator and using it according to the driving condition. Figure 24 shows the line temperature for the power-split HHV and the power-split HST with a cooler having cooling performance as in Figure 13. Both systems have a stable working temperature with a cooler and the thermal model properly simulates the thermal behavior of hydraulic systems. For the average temperature, the power-split HHV has a lower system temperature than the power-split HST, even though it shows large temperature fluctuation in the high pressure line due to the rapid pressure change with accumulators. The temperature results show that not only does the power-split HHV make it easier to manage heat, it also has possibilities of saving energy for cooling the system and costs by using a smaller capacitance cooler.

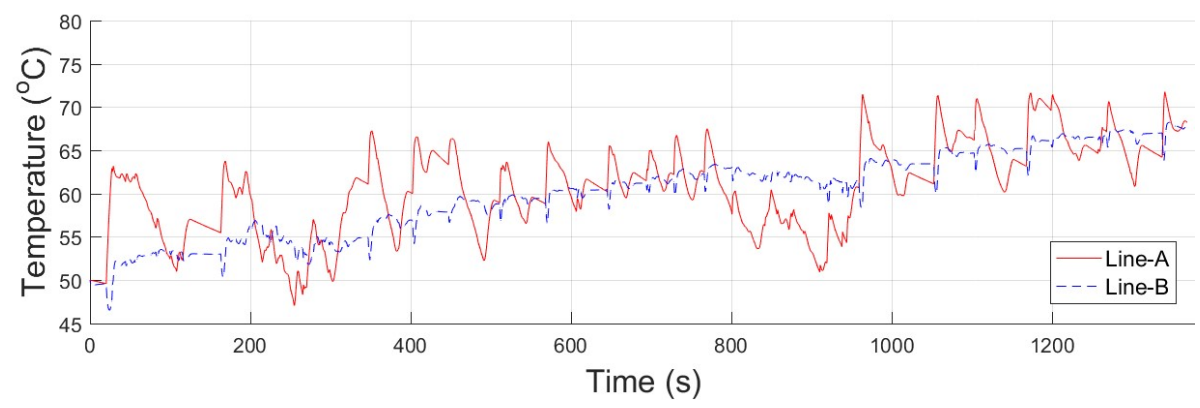

(a)

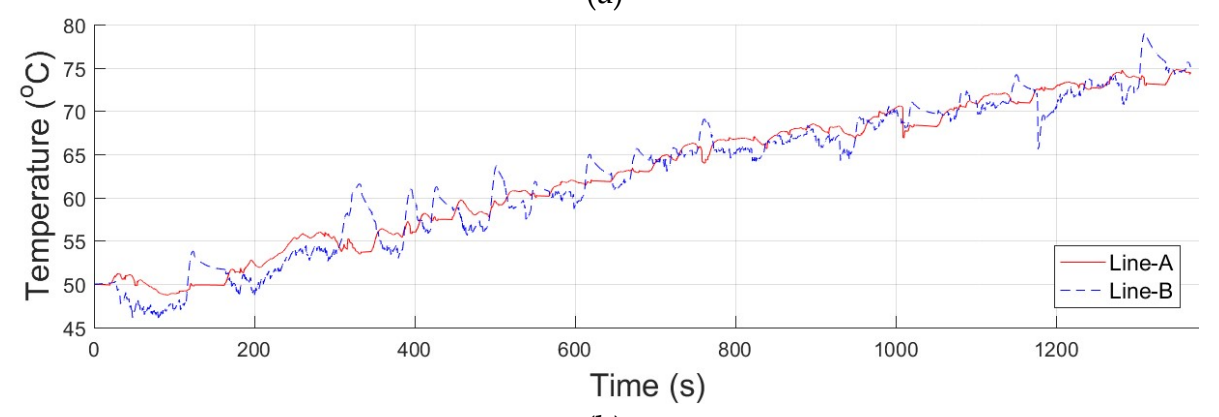

(b)

Figure 23. Line temperature without cooling for (a) power-split HHV and (b) power-split HST.

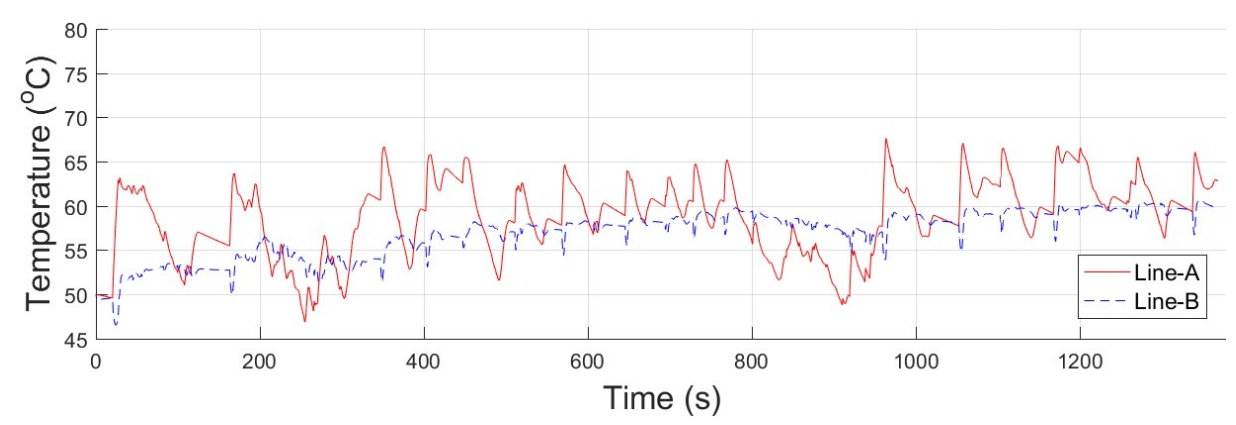

(a)

Figure 24. Cont. 


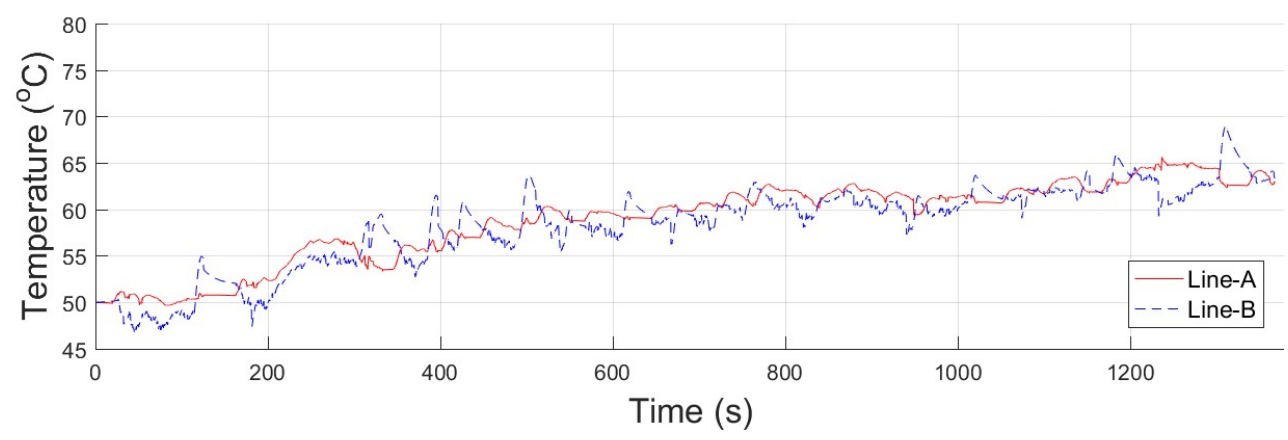

(b)

Figure 24. Line temperature with cooling for (a) power-split HHV and (b) power-split HST.

In conclusion, power-split HHVs show a possibility of better energy saving by regenerative energy during braking, and engine idling management. The results by thermal modeling show better thermal management for power-split HHV by reducing the waste of the energy during braking, which makes the hydraulic system more thermally stable and reduces energy for system cool-down. The power-split HHV characteristics analyzed in this study can be used to design and organize the system control logic while developing power-split HHVs.

\section{Conclusions}

In this paper, the details of energy management characteristics of power-split HHVs were analyzed, including those not thoroughly studied in the past. A novel simulation method for dynamic and thermal behaviors was firstly introduced and applied for analyzing dynamical and thermal characteristics together, which affects the energy savings of the systems. The results show not only less energy consumption for power-split HHVs but also energy-saving possibilities of engine idling time and thermal management. The results for the power-split HHV show more chances for engine idling, which directly related to fuel consumption savings by engine stop. More engine idling time enables the system to operate in a more efficient area on the engine map by load leveling. The results for the system temperature for the power-split HHV show possibilities of better thermal management by preventing waste of braking power, which is especially crucial for hydraulic systems in comparison to other kinds of power delivery systems. The ease of thermal management results in better thermal stability with lower system temperature, as well as less energy consumption for cooling down the system with minimizing the cooler system. The detailed characteristics of power-split HHVs analyzed in this study can be used for designing and organizing system control logic for energy management while developing power-split HHVs.

Author Contributions: All authors contributed to this work in collaboration. The first author, H.K., conducted the conceptualization, literature review, and system modeling and wrote the manuscript. The second author, M.I., provided project administration, supervision, and feedback on the research. All authors have read and agreed to the published version of the manuscript.

Funding: This research received no external funding.

Conflicts of Interest: The authors declare no conflict of interest.

\section{Abbreviations}

FTP Federal test procedure

HHV Hydraulic hybrid vehicle

HP High pressure

HST Hydrostatic transmission

LP Low pressure

UDDS Urban dynamometer driving schedule 


\section{References}

1. Baseley, S.; Ehret, C.; Greif, E.; Kliffken, M.G. Hydraulic hybrid systems for commercial vehicles. SAE Tech. Pap. 2007, 1, 4150.

2. Li, C.-T.; Peng, H. Optimal configuration design for hydraulic split hybrid vehicles. In Proceedings of the 2010 American Control Conference, Baltimore, MD, USA, 30 June-2 July 2010; pp. 5812-5817.

3. Daher, N.; Ivantysynova, M. Energy analysis of an original steering technology that saves fuel and boosts efficiency. Energy Convers. Manag. 2014, 86, 1059-1068. [CrossRef]

4. Chen, Q.; Lin, T.; Ren, H.; Fu, S. Novel potential energy regeneration systems for hybrid hydraulic excavators. Math. Comput. Simul. 2019, 163, 130-145. [CrossRef]

5. Yu, Y.X.; Ahn, K.K. Optimization of energy regeneration of hybrid hydraulic excavator boom system. Energy Convers. Manag. 2019, 183, 26-34. [CrossRef]

6. Minav, T.; Heikkinen, J.; Schimmel, T.; Pietola, M. Direct driven hydraulic drive: Effect of oil on efficiency in sub-zero conditions. Energies 2019, 12, 219. [CrossRef]

7. An, K.; Kang, H.; An, Y.; Park, J.; Lee, J. Methodology of excavator system energy flow-down. Energies 2020, 13, 951. [CrossRef]

8. Bender, F.A.; Bosse, T.; Sawodny, O. An investigation on the fuel savings potential of hybrid hydraulic refuse collection vehicles. Waste Manag. 2014, 34, 1577-1583. [CrossRef]

9. Heskitt, M.; Smith, T.; Hopkins, J. Design \& Development of the LCO-140H Series Hydraulic Hybrid Low Floor Transit Bus; Federal Transit Administration: Washing, DC, USA, 2012.

10. Ramdan, M.I.; Stelson, K.A. Optimal design of a power-split hybrid hydraulic bus. Proc. Inst. Mech. Eng. Part D J. Automob. Eng. 2016, 230, 1699-1718. [CrossRef]

11. Bravo, R.R.S.; De Negri, V.J.; Oliveira, A.A.M. Design and analysis of a parallel hydraulic - pneumatic regenerative braking system for heavy-duty hybrid vehicles. Appl. Energy 2018, 225, 60-77. [CrossRef]

12. Pugi, L.; Pagliai, M.; Nocentini, A.; Lutzemberger, G.; Pretto, A. Design of a hydraulic servo-actuation fed by a regenerative braking system. Appl. Energy 2017, 187, 96-115. [CrossRef]

13. Wu, W.; Hu, J.; Jing, C.; Jiang, Z.; Yuan, S. Investigation of energy efficient hydraulic hybrid propulsion system for automobiles. Energy 2014, 73, 497-505. [CrossRef]

14. Ramakrishnan, R.; Hiremath, S.S.; Singaperumal, M. Design strategy for improving the energy efficiency in series hydraulic/electric synergy system. Energy 2014, 67, 422-434. [CrossRef]

15. Hui, S.; Lifu, Y.; Junqing, J.; Yanling, L. Control strategy of hydraulic/electric synergy system in heavy hybrid vehicles. Energy Convers. Manag. 2011, 52, 668-674. [CrossRef]

16. Wang, Z.; Jiao, X.; Pu, Z.; Han, L. Energy recovery and reuse management for fuel-electric-hydraulic hybrid powertrain of a construction vehicle. IFAC-PapersOnLine 2018, 51, 390-393. [CrossRef]

17. Gong, J.; Zhang, D.; Guo, Y.; Liu, C.; Zhao, Y.; Hu, P.; Quan, W. Power control strategy and performance evaluation of a novel electro-hydraulic energy-saving system. Appl. Energy 2019, 233-234, 724-734. [CrossRef]

18. Du, Z.; Cheong, K.L.; Li, P.Y.; Chase, T.R. Fuel Economy Comparisons of Series, Parallel and HMT hydraulic hybrid architectures. In Proceedings of the 2013 American Control Conference, Washington, DC, USA, 17-19 June 2013; pp. 5974-5979.

19. Wang, Y.; Zeng, X.; Song, D.; Yang, N. Optimal rule design methodology for energy management strategy of a power-split hybrid electric bus. Energy 2019, 185, 1086-1099. [CrossRef]

20. Pei, H.; Hu, X.; Yang, Y.; Tang, X.; Hou, C.; Cao, D. Configuration optimization for improving fuel efficiency of power split hybrid powertrains with a single planetary gear. Appl. Energy 2018, 214, 103-116. [CrossRef]

21. Sim, T.P.; Li, P.Y. Analysis and control design of a hydro-mechanical hydraulic hybrid passenger vehicle. In Proceedings of the ASME 2009 Dynamic Systems and Control Conference, Hollywood, CA, USA, 12-14 October 2009; pp. 667-674.

22. Li, P.Y. Optimization and control of a hydro-mechanical transmission based hybrid hydraulic passenger vehicle. In Proceedings of the 7th International Fluid Power Conference, Aachen, Germany, 22-24 March 2010.

23. Cheong, K.L.; Li, P.Y.; Chase, T.R. Optimal design of power-split transmissions for hydraulic hybrid passenger vehicles. In Proceedings of the 2011 American Control Conference, San Francisco, CA, USA, 29 June-1 July 2011; pp. 3295-3300. 
24. Zhang, H.; Wang, F.; Stelson, K.A. Modeling and design of a hydraulic hybrid powertrain for passenger vehicle. In Proceedings of the ASME/BATH 2017 Symposium on Fluid Power and Motion Control, Sarasota, FL, USA, 16-19 October 2017.

25. Cheong, K.L.; Du, Z.; Li, P.Y.; Chase, T.R. Hierarchical control strategy for a hybrid hydro-mechanical transmission (HMT) power-train. In Proceedings of the American Control Conference, Portland, OR, USA, 4-6 June 2014; pp. 4599-4604.

26. Kumar, R.; Ivantysynova, M. An optimal power management strategy for hydraulic hybrid output coupled power-split transmission. In Proceedings of the ASME Dynamic Systems and Control Conference, Hollywood, CA, USA, 12-14 October 2009; pp. 299-306.

27. Kumar, R.; Ivantysynova, M. The hydraulic hybrid alternative for Toyota Prius-A power management strategy for improved fuel economy. In Proceedings of the 7th International Fluid Power Conference, Aachen, Germany, 22-24 March 2010.

28. Lammert, M.P.; Burton, J.; Sindler, P.; Duran, A. Hydraulic hybrid and conventional parcel delivery vehicles' measured laboratory fuel economy on targeted drive cycles. SAE Int. J. Altern. Powertrains 2015, 4, 11-19. [CrossRef]

29. Wasbari, F.; Bakar, R.A.; Gan, L.M.; Tahir, M.M.; Yusof, A.A. A review of compressed-air hybrid technology in vehicle system. Renew. Sustain. Energy Rev. 2017, 67, 935-953. [CrossRef]

30. Macor, A.; Benato, A.; Rossetti, A.; Bettio, Z. Study and simulation of a hydraulic hybrid powertrain. Energy Procedia 2017, 126, 1131-1138. [CrossRef]

31. Kwon, H.; Sprengel, M.; Ivantysynova, M. Thermal modeling of a hydraulic hybrid vehicle transmission based on thermodynamic analysis. Energy 2016, 116, 650-660. [CrossRef]

32. Panchal, S.; Dincer, I.; Agelin-Chaab, M. Thermodynamic analysis of hydraulic braking energy recovery systems for a vehicle. J. Energy Resour. Technol. 2016, 138, 011601. [CrossRef]

33. Kwon, H.; Ivantysynova, M. System and thermal modeling for a novel on-road hydraulic hybrid vehicle by comparison with measurements in the vehicle. In Proceedings of the ASME/BATH 2017 Symposium on Fluid Power and Motion Control, Sarasota, FL, USA, 16-19 October 2017.

34. Kwon, H.; Keller, N.; Ivantysynova, M. Thermal management of open and closed circuit hydraulic hybrids-A comparison study. In Proceedings of the 11th IFK International Conference on Fluid Power, Aachen, Germany, 19-21 March 2018.

35. Wu, G.; Zhang, X.; Dong, Z. Powertrain architectures of electrified vehicles: Review, classification and comparison. J. Franklin Inst. 2015, 352, 425-448. [CrossRef]

36. Conlon, B. Comparative analysis of single and combined hybrid electrically variable transmission operating modes. In Proceedings of the SAE 2005 World Congress and Exhibition, Detroit, MI, USA, 11-14 April 2005.

37. Bhattacharya, T.K.; Chandra, R.; Mishra, T.N. Performance characteristics of a stationary constant speed compression ignition engine on alcohol-diesel microemulsions. Agric. Eng. Int. CIGR Ejournal 2006, 8, 1-18.

38. Bhavesh, V.; Rathod, G.P.; Patel, T.M. Performance characteristics of constant speed diesel engine by using of HHO gas and varying injection pressure. Indian J. Res. 2016, 5, 91-94.

39. Ivantysyn, J.; Ivantysynova, M. Hydrostatic Pumps and Motors; Akademia Books International: Delhi, India, 2001.

40. Shang, L.; Ivantysynova, M. Scaling criteria for axial piston machines based on thermo-elastohydrodynamic effects in the tribological interfaces. Energies 2018, 11, 3210. [CrossRef]

41. Klop, R.; Ivantysynova, M. Investigation of noise sources on a series hybrid transmission. Int. J. Fluid Power 2011, 12, 17-30. [CrossRef]

42. Boetcher, S.K.S. Natural Convection from Circular Cylinders; Springer: Berlin, Germany, 2014.

43. Stephan, P.; Kabelac, S.; Kind, M.; Martin, H.; Mewes, D.; Schaber, K. VDI Heat Atlas; Springer: Berlin, Germany, 2014.

44. Churchill, S.W.; Chu, H.H.S. Correlating equations for laminar and turbulent free convection from a vertical plate. Int. J. Heat Mass Transf. 1975, 18, 1323-1329. [CrossRef]

45. Sparrow, E.M.; Stretton, A.J. Natural convection from variously oriented cubes and from other bodies of unity aspect ratio. Int. J. Heat Mass Transf. 1985, 28, 741-752. [CrossRef]

46. Oppermann, M. A New Approach for Failure Prediction in Mobile Hydraulic Systems; VDI-Verlag: Düsseldorf, Germany, 2007. 
47. Sprengel, M. Influence of Architecture Design on the Performance and Fuel Efficiency of Hydraulic Hybrid Transmissions. Ph.D. Thesis, Purdue University, West Lafayette, IN, USA, 2015.

48. Incropera, F.P.; DeWitt, D.P. Fundamentals of Heat and Mass Transfer; Wiley: Hoboken, NJ, USA, 2001.

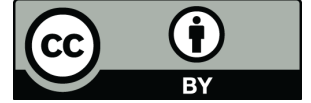

(C) 2020 by the authors. Licensee MDPI, Basel, Switzerland. This article is an open access article distributed under the terms and conditions of the Creative Commons Attribution (CC BY) license (http://creativecommons.org/licenses/by/4.0/). 